\title{
10. COMPARISON OF SHIPBOARD VS. SHORE-BASED SPECTRAL DATA FROM AMAZON FAN CORES: IMPLICATIONS FOR INTERPRETING SEDIMENT COMPOSITION ${ }^{1}$
}

\author{
William L. Balsam, ${ }^{2}$ John E. Damuth, ${ }^{2}$ and Ralph R. Schneider ${ }^{3}$
}

\begin{abstract}
Reflectance spectrophotometry potentially provides a rapid method of investigating the changing characteristics and composition of marine sediments. Recognizing this, the Ocean Drilling Program has permanently deployed a commercially available, handheld spectrophotometer, the Minolta CM-2002, aboard the JOIDES Resolution. The present study evaluated shipboard spectral data obtained from Amazon Fan cores during Leg 155 using the Minolta instrument. These data were compared to spectra measured from comparable Leg 155 core samples using a shore-based, research-grade, Perkin-Elmer Lambda 6 spectrophotometer. The spectral signal is muted in the percent-reflectance curves from the wet sediments analyzed aboard ship when compared to percent-reflectance curves generated from dry core samples on shore. However, when both sets of reflectance curves are processed using a first-derivative transformation, shipboard and shore-based analyses are quite similar and suggest that useful, accurate spectral data can be obtained from wet core sediments at sea. This observation is further supported by factor analysis of parallel (shipboard vs. shore-based) data sets $(400-700 \mathrm{~nm})$ produced by the two instruments. The same four factors are present in both data sets, but do not necessarily explain a similar amount of variance. These factors are related to hematite plus goethite, clay minerals, organic matter, and carbonate content.

The shore-based spectral data set was subjected to further factor analysis to determine if additional compositional information could be extracted using the increased accuracy and extended wavelength range (250-850 $\mathrm{nm}$ ) of the laboratory instrument. This analysis produced one additional factor, probably chlorite; separated hematite and goethite into two factors; and clarified the nature of the clay mineral factor as probably a combination of illite and montmorillonite. By calculating factor scores, semiquantitative estimates of concentrations of variations of these sediment components were calculated downhole for several Leg 155 sites. The Amazon Fan sediments represent a rigorous test of the spectral technique because most of the sediments are dark and show little variation in the visible region of the electromagnetic spectrum. Nevertheless, it was possible to extract compositional information from the spectra.

Our investigations also lead us to make the following important recommendations for using the Minolta CM-2002 spectrophotometer at sea. First, if wet core surfaces must be covered with plastic film during spectral measurements to protect the instrument, only Glad Cling Wrap (a brand of clear plastic food wrap) should be used because this brand does not significantly distort the spectra of the sediments. Second, when calibrating the Minolta instrument, the white calibration cap should not be covered by the clear plastic wrap used to cover the cores. Third, the Minolta instrument should be set to exclude the specular component (SCE setting) for all measurements, and the optional granular-materials cover for the instrument (CM-A40) should not be used. These recommendations will ensure that the spectral data can be compared directly to data generated by laboratory-grade spectrophotometers.
\end{abstract}

\section{INTRODUCTION AND PREVIOUS WORK}

Marine geologists have used color to describe marine sediment cores for many years. Color is the human eye's perception of reflected radiation in the visible region of the electromagnetic spectrum (VIS, 400-700 nm). Sediment color is usually determined by comparison to a color chart like the Geological Society of America Rock Color Chart (Goddard et al., 1948), which is a derivative of the Munsell Color Chart. However, such color-chart analysis is inexact because no two observers have the same color perception. Color also tends to obscure differences in VIS spectra because similar colors may result from the mixing of different spectral wavelengths. Many of the problems related to color analysis can be overcome by using diffuse-reflectance spectrophotometry, a technique in which light reflected from a sample is collected in a reflectance sphere and compared to light reflected from a pure white standard throughout the

${ }^{1}$ Flood, R.D., Piper, D.J.W., Klaus, A., and Peterson, L.C. (Eds.), 1997. Proc. ODP, Sci. Results, 155: College Station, TX (Ocean Drilling Program).

${ }^{2}$ Department of Geology, P.O. Box 19049, University of Texas at Arlington, Arlington, TX 76019, U.S.A. balsam@uta.edu and jedamuth@utarlg.uta.edu

${ }^{3}$ Fachbereich Geowissenschaften, Universität Bremen, Postfach 330440, D-28334 Bremen, Federal Republic of Germany. wavelength range being analyzed. The data produced by this technique are reflectance as a function of wavelength relative to a standard.

Attempts to use reflectance spectra without respect to color to interpret marine cores date back to the mid-1960s (Chester and Elderfield, 1966, 1968; Chester and Green, 1968); however, a concerted effort to exploit near ultraviolet, visible, and near infrared (NUV/ VIS/NIR) spectral reflectance as a marine geological research tool has only recently been undertaken. Deaton (1987) quantified Munsell color-chart chips with a reflectance spectrophotometer in an attempt to help geologists relate color to spectra. Although such analysis of color chips makes the determination of color more precise, it does not alleviate the problems associated with the scientific use of color. Studies by Barranco et al. (1989), Deaton and Balsam (1991), Balsam and Deaton (1991, 1996), Herbert et al. (1992), and Mix et al. (1992) have shown that many marine sediment components have distinctive spectral signatures. VIS reflectance spectra have been used to identify the iron oxide and oxyhydroxide minerals hematite and goethite, the clay minerals illite, montmorillonite and chlorite, calcite, and sediment organic content (Deaton and Balsam, 1991; Balsam and Deaton, 1991, 1996). Infrared reflectance spectra identified using a Fourier Transform Infrared Spectrophotometer (FTIR) were utilized to quantify the abundances of a number of minerals including calcite, quartz, and different clay minerals (Herbert et al., 1992). 
Both the reflectance spectrophotometer used by Balsam and Deaton and the FTIR used by Herbert et al. analyze only one sample at a time, and each sample then has to be changed manually. Both machines take about $60 \mathrm{~s}$ to analyze a sample; the FTIR actually performs a single analysis in $5 \mathrm{~s}$, but uses numerous stacked analyses to remove noise. Mix et al. $(1992,1995)$ developed a VIS/NIR scanning spectrophotometer that can be deployed at sea. This instrument has been utilized to scan cores aboard the JOIDES Resolution and is capable of analyzing a small area of a core's surface (about a $2-\mathrm{cm}$ circle) in $5 \mathrm{~s}$, then automatically advancing down the core and making subsequent measurements. In addition, compact, handheld spectrophotometers, such as the Minolta CM-2002, which was used in the present study (see below) are also available. A Minolta CM-2002 has also been routinely used to measure color spectra of core sediments on several Ocean Drilling Program legs, including Leg 155 discussed in this study (e.g., Schneider et al., 1995). Despite these differences in instrumentation, the ultimate goal of spectrophotometry studies is to provide accurate, qualitative, and quantitative estimates of sediment composition.

Leg 155 was the first Ocean Drilling Program leg where sediment cores were analyzed by both the handheld shipboard spectrophotometer, a Minolta CM-2002, aboard the JOIDES Resolution and a shorebased, research-grade spectrophotometer, a Perkin-Elmer Lambda 6, at the University of Texas at Arlington. Comparable databases were assembled from both the shipboard and shore-based instruments to address three general categories of questions:

1. Are the results of the shore-based and shipboard instruments comparable? If not, how and why do they differ? Does the limited wavelength range and sensitivity of the shipboard instrument exclude the identification of some sediment components?

2. Can the techniques used to gather data aboard ship with the Minolta spectrophotometer be improved to provide data comparable to that of the shore-based spectrophotometer?

3. What can be learned about the composition and mineralogy of Amazon Fan sediment from spectral analysis?

\section{COMPARISON OF SHIPBOARD AND SHORE-BASED SPECTRAL ANALYSES}

One major objective of this study is to compare spectral analyses obtained by the shipboard (Minolta CM-2002) and shore-based (Perkin-Elmer Lambda 6) instruments. Any comparison of shipboard and shore-based spectral analyses must take into account differences in instrumentation and differences related to the nature of the samples.

\section{Differences in Instrumentation}

The major differences between the shipboard and shore-based instruments are listed in Table 1. Two of the differences listed, standard and light source, present potential problems when comparing results from the Minolta and Perkin-Elmer spectrophotometers. In addition, a setting on the Minolta (SCE vs. SCI) must also be addressed.

\section{Standards}

Standards and instrument calibration are intimately related. Although the calibration procedure for both instruments is similar, subtle differences in calibration may cause large variations in spectral readings. The Perkin-Elmer Lambda 6 uses barium sulfate plates to set the $100 \%$ reflectance level. Because the Perkin-Elmer's sample compartment is light-tight, the zero-percent level does not have to be set. In contrast, a white ceramic tile cap attachment is used for calibrating the Minolta CM-2002. The cap itself does not set the 100\% level; rather, the cap is a ceramic transfer standard that is physically calibrated against a primary barium-sulfate standard. The absolute reflectance of this primary $\mathrm{BaSO}_{4}$ standard as determined at the National Physical Laboratory in the United Kingdom is used for reference. This primary standard is a pressed $\mathrm{BaSO}_{4}$ plate formed according to ISO 7724/2. The absolute reflectance values relative to the primary $\mathrm{BaSO}_{4}$ standard at 31 wavelengths $(400-700 \mathrm{~nm}$ at $10 \mathrm{~nm}$ intervals) for the ceramic tile cap are stored on the memory card of the Minolta. When a white calibration is performed, the instrument sets the reflectance at each wavelength to its stored value relative to the standard (E. Becker, Product Line Manager, Minolta Instrument Systems, pers. comm., 1995, 1996). In addition to white calibration, it is also necessary to set the zero-percent level on the Minolta, either by using a black box or by pointing the instrument into a void.

If calibrations for the Minolta and Perkin-Elmer differ, they could bias comparison of reflectance values measured by the two instruments. As an experiment, we calibrated a Minolta CM-2002 instrument (identical to the ones used aboard JOIDES Resolution) using the white tile calibration cap supplied by Minolta, then analyzed a white $\mathrm{BaSO}_{4}$ standard plate used to calibrate the Perkin-Elmer spectrophotometer. The $\mathrm{BaSO}_{4}$ plate exhibited uniformly high values, except at the violet end of the spectrum $(400-450 \mathrm{~nm})$, where reflectance values decreased a few percent (Fig. 1). Thus, the Minolta seems to slightly suppress violet wavelengths relative to the Perkin-Elmer. Several factors probably contribute to the difference in readings of $\mathrm{BaSO}_{4}$ obtained with the Minolta and Perkin-Elmer instruments. Instrument geometry, band width, age of the $\mathrm{BaSO}_{4}$ plate, age of the integrating sphere, and source of the $\mathrm{BaSO}_{4}$ all may contribute small deviations in setting the $100 \%$ level. We are currently analyzing a variety of $\mathrm{BaSO}_{4}$ standards to determine the range of spectral variation that can be expected with these instruments.

\section{Light Source}

The Minolta instrument uses a Xenon pulse light source, whereas the Perkin-Elmer uses a tungsten filament light source for visible (VIS, 400-700 nm) and near infrared (NIR, 700-850 nm) wavelengths, and a deuterium light source for near ultraviolet (NUV, 250-

Table 1. Differences in instrumentation.

\begin{tabular}{lll}
\hline \multicolumn{1}{c}{ Spectrophotometer } & \multicolumn{1}{c}{ Minolta CM-2002 } & \multicolumn{1}{c}{ Perkin-Elmer Lambda 6 } \\
\hline Location & Shipboard JOIDES Resolution & Shore-based University of Texas at Arlington \\
Operation & Mobile-handheld, field or lab use & Stationary in laboratory \\
Wavelength range & $400-700 \mathrm{~nm}$ & $250-850$ nm (diffuse reflectance mode) \\
Data recording interval & $10 \mathrm{~nm}$ (= wavelength pitch) & $1 \mathrm{~nm}$ \\
Minimum slit width & $15 \mathrm{~nm}$ (= half-bandwidth) & $1 \mathrm{~nm}$ (2-nm slit width used in analyses) \\
Analysis time & $\sim 3 \mathrm{~s}$ & $\sim 120 \mathrm{~s}$ \\
Standard & White ceramic tile cap, which is a transfer standard related to $\mathrm{BaSO}_{4}$ & $\mathrm{BaSO}_{4}$ plate \\
Light source & Xenon pulse lamp & Tungsten lamp (VIS and NIR); deuterium lamp (NUV) \\
Specular component & Choice to include (SCI setting) or to exclude (SCE setting) & Excluded-diffuse reflectance mode only \\
\hline
\end{tabular}




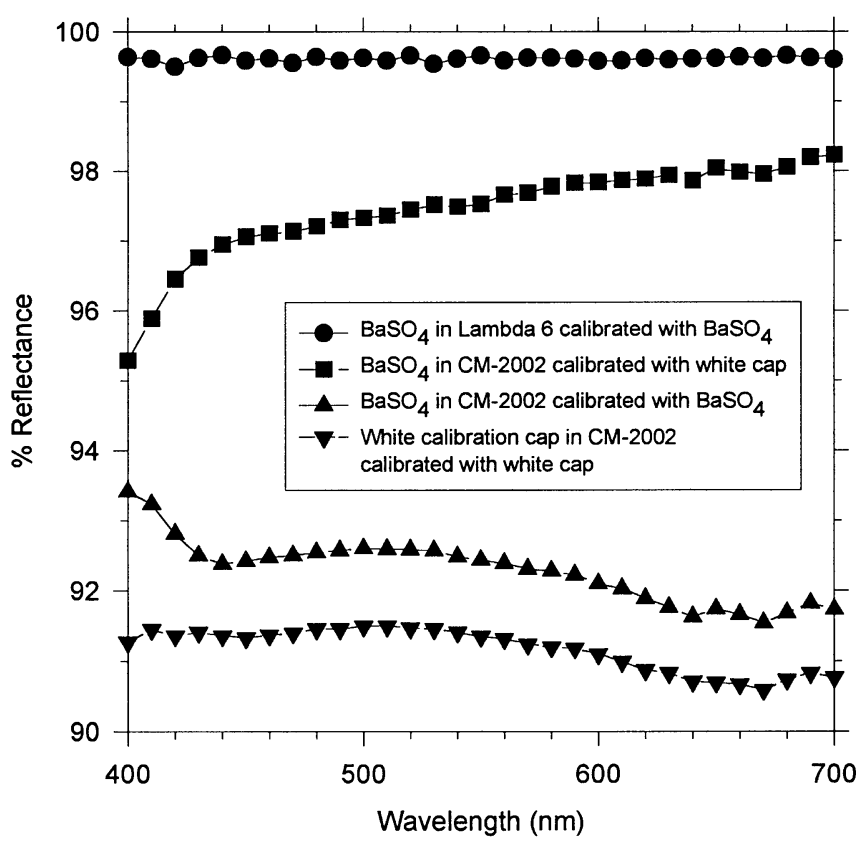

Figure 1. Comparison of reflectance values measured from the $\mathrm{BaSO}_{4}$ standard plate using the Minolta CM-2002 and the Perkin-Elmer Lambda 6 spectrophotometer. The $\mathrm{BaSO}_{4}$ plate is used as the standard to set the $100 \%$ level on the Perkin-Elmer Lambda 6 instrument. Note that the $\mathrm{BaSO}_{4}$ exhibits uniformly high values ( 99.58\%) across the entire spectrum for the Lambda 6 (top curve, solid circles); however, these values vary slightly $(99.50 \%$ to $99.66 \%$ ) and are not $100 \%$ because of variations in the placement of the $\mathrm{BaSO}_{4}$ plate in the instrument's sample holder. These small variations in reflectance are not significant. In contrast, when the Minolta instrument is calibrated with its white calibration cap as suggested in the instruction manual, reflectance values measured with the $\mathrm{BaSO}_{4}$ plate fall off at the violet end of the spectrum (solid squares). Calibration of the Minolta instrument using the $\mathrm{BaSO}_{4}$ plate instead of the white calibration cap produced an increase in values at the violet end of the spectrum (solid triangles). The bottom curve (inverted solid triangles) shows the reflectance spectrum produced by the Minolta instrument when the white cap was used for calibration as per the instruction manual; these reflectance values should be identical to the calibration data supplied with the cap.

$400 \mathrm{~nm}$ ) wavelengths. Differences in the light sources could potentially bias results, although calibration should, theoretically, remove many of the differences.

\section{SCE vs. SCI Settings}

The Minolta CM-2002 has a switch that allows the specular component to be included (SCI) or excluded (SCE); the Perkin-Elmer instrument excludes the specular component (SCE). Specular reflectance is perfect reflectance (e.g., reflectance from a mirror). Including the specular component essentially includes glare and provides a better estimate of color as seen by the human eye. However, glare does not contribute to the spectrum, and, therefore, including the specular component (SCI setting) makes comparison to data from a laboratory spectrophotometer such as the Perkin-Elmer difficult because most of these instruments read only diffuse reflectance. Thus, setting the Minolta instrument on the SCE setting facilitates comparison with laboratory instruments. Diffuse reflectance is the result of scattering from an irregular surface and the collection of scattered and reflected light in a reflectance sphere. The SCE setting is de- signed to read only diffuse reflectance, and Minolta considers this setting to be a better all-purpose setting. The SCI setting is designed to read both diffuse and specular reflectance. In the manual for operation of the CM-2002 spectrophotometer, Minolta points out that the SCI setting is most useful for doing color mixing or computer color matching, whereas the SCE setting more closely matches that of visual examination and is good for a wide variety of subjects, both with and without gloss.

\section{Differences in Condition of Samples}

\section{Wetness and Surface Roughness}

Shipboard analyses were performed on wet core surfaces created by splitting the core with a metal wire. The roughness of the core surfaces varied mainly because of changes in grain size (clay to gravel size range). In contrast, the shore-based analyses used ground, dried core samples, which were then mixed into a slurry on glass slides with distilled water and slowly dried (see Barranco et al., 1989, for details of sample preparation). As demonstrated by Schneider et al. (1995), one of the primary results of drying of a core surface is an increase in reflectance. The grinding of samples during slide preparation produces a number of effects, including a homogeneous distribution of sediment components and a smooth surface.

In preparation for shipboard core analyses using the Minolta instrument, core surfaces were covered with Saran Wrap, a commercial brand of plastic food wrap, to protect the instrument from water and wet sediment. The need to use Saran Wrap required that we assess the effect of the Saran Wrap on the spectra of the cores. Thus, we performed an experiment in which we wrapped a $\mathrm{BaSO}_{4}$ standard from the P-E Lambda 6 spectrophotometer with Saran Wrap and determined the reflectance in the visible portion of the spectrum. Ideally, a clear film used to cover cores should transmit light uniformly across the visible wavelengths of the electromagnetic spectrum with little loss through absorption. Our tests show that Saran Wrap does not meet this criterion because it causes preferential absorption in some wavelengths and exhibits a general trend of decreasing reflectance toward the violet end of the spectrum (Fig. 2). As a result of these tests, we examined several other commercially available clear films, mainly other brands of plastic food wrap. Of the films tested, Glad Cling Wrap (crystal clear polyethylene) turned out to be ideal. Spectral curves obtained through Glad Cling Wrap exhibit routinely high reflectance across the entire visible portion of the spectrum. Based on the limited number of samples we tested, Glad appears to be very consistent in its spectral behavior (Fig. 2). As a result of these tests, we strongly recommend that Glad Cling Wrap be used rather than some other brand of plastic film when analyzing wet core surfaces with the Minolta instrument. Our tests suggest that the decrease in reflectance values at the violet end of the spectrum noted by Schneider et al. (1995) for Leg 155 sediments probably results from the combined effect of covering cores with Saran Wrap and the Minolta spectrophotometer's tendency to fall off in these wavelengths relative to the Perkin-Elmer instrument (see above).

\section{Oxidation of Sediments}

Split cores aboard ship not only dry out while being described and processed, but also oxidize. Oxidation may have a number of effects. One common sediment component that oxidizes is organic matter. Unoxidized organic matter is dark, and as it oxidizes, the sediment that contains it becomes lighter, usually changing from dark to light gray (Deaton and Balsam, 1993). This color change may also result from the oxidation of reduced iron compounds to iron oxides and oxyhydroxides. The oxidation of iron compounds has the potential to lighten sediment and to increase reflectance at the red end of the spectrum. 


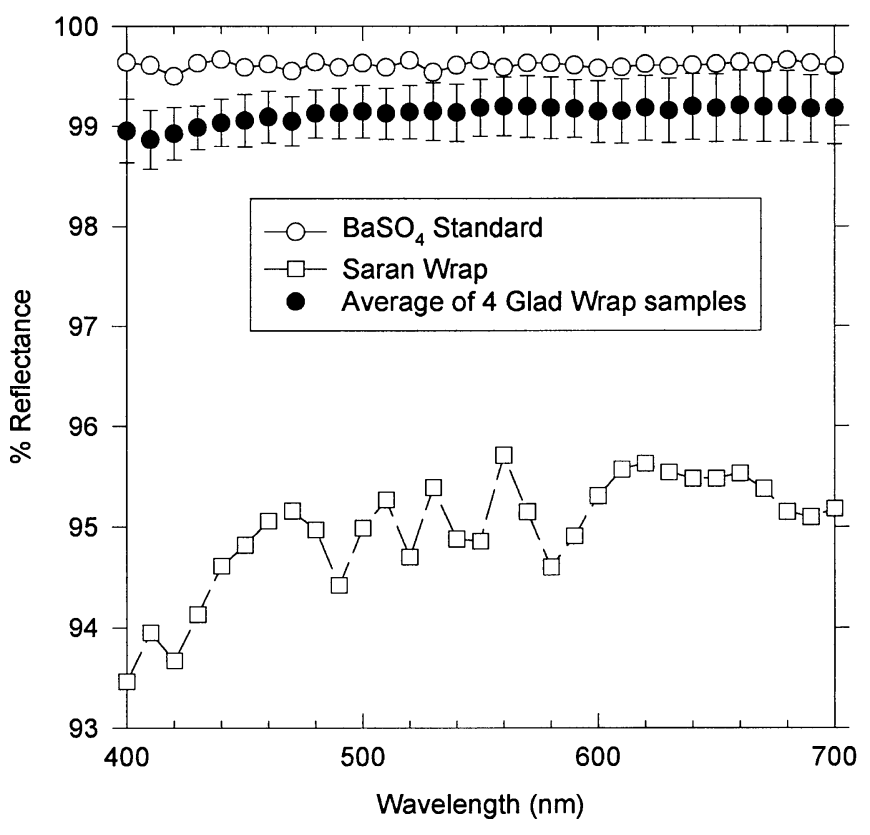

Figure 2. Comparison of the effects of using plastic food wrap on VIS spectral measurements. Reflectance spectra from Glad Cling Wrap (solid circles) and Saran Wrap (open squares) covering a $\mathrm{BaSO}_{4}$ plate analyzed in the Perkin-Elmer Lambda 6 instrument. The top curve (open circles) is a reflectance curve measured from an uncovered $\mathrm{BaSO}_{4}$ standard plate. Solid circles show the average values (plus standard deviations) for samples from four different rolls of Glad Cling Wrap. Glad Cling Wrap transmits a substantial portion of the light without preferential absorption of the spectra. (Note: several additional samples of Glad Cling Wrap analyzed, but not shown on this diagram, all exhibited characteristics similar to the four samples shown). In contrast, the Saran Wrap causes variable absorption throughout the VIS and exhibits a general trend of decreasing reflectance toward the violet end of the spectrum.

Because of drying and oxidation, samples constantly become lighter (increasing in reflectance) and thus change color. Analysis of wet samples, therefore, presents a "moving target" and yields results that cannot be reproduced later in the lab. Dried samples yield reproducible results, but may not correlate to the color of the wet sample.

\section{Resolution of Problems Comparing Shipboard vs. Shore-Based Results}

Clearly, some of the problems inherent in the comparison of shipboard and shore-based data cannot be resolved. Differences in wet vs. dry, oxidized vs. unoxidized, type of standard, and nature of the light source must be taken into account. The effect of many of these differences is to alter the reflectance (i.e., making samples either lighter or darker), but not necessarily to change the relative importance of the various wavelengths. As long as the reflectance changes are uniform across the spectrum, and are not concentrated in one or a few wavelength bands, then their effect may be negligible.

However, percent reflectance curves are difficult to compare because they are smooth and change gradually. Reflectance curves from marine sediments typically increase slowly from 400 to $700 \mathrm{~nm}$ and contain no pronounced peaks or valleys (Figs. 3, 4; top; see also Balsam and Deaton, 1991; Balsam and Wolhart, 1993). One method for reducing the importance of absolute percent reflectance values, and thereby making the curves easier to compare, is to calculate changes in the slope of the curve by taking the first derivative of the percent reflectance curve (Figs. 3, 4; bottom; Barranco et al., 1989; Balsam and Deaton, 1991; Deaton and Balsam, 1991). First-deriva- tive values are high where the slope of the percent reflectance curve changes rapidly. We routinely calculated first-derivative values at 10-nm sample intervals from 400 to $700 \mathrm{~nm}$ for each shore-based and shipboard analysis. The resulting 30 values obtained from each analysis are then plotted at the midpoint of each 10-nm interval (i.e., the 400 to 410 value is plotted at 405 , etc.) and are expressed as $\% / \mathrm{nm}$ (Figs. 3, 4: bottom). Typically, first-derivative curves contain more peaks than reflectance curves. Barranco et al.(1989), Deaton and Balsam (1991), and Balsam and Deaton $(1991,1996)$ have shown that the positions of peaks on the first-derivative curves are indicative of sediment composition and mineralogy.

Although first-derivative curves provide substantial compositional information about many samples, they are not useful for samples with uniform reflectance across the wavelength range of the analysis. For example, white material like carbonate, opaline silica, or quartz exhibits routinely high reflectance in the entire VIS (this is why the eye perceives these materials as white). First-derivative curves for these materials exhibit little change in the VIS, although all these white materials have useful reflectance changes in the NUV and NIR (Herbert et al., 1992; Gaffey, 1985). Similarly, very dark material exhibits consistently low values throughout the VIS, and first-derivative curves contain few peaks. Clearly, VIS spectrophotometry may not be a useful technique for distinguishing white or black sediment. Because Amazon Fan sediments are typically dark in color they represent a difficult test for spectral analysis.

\section{Test Comparison of Wet and Dry Sediments}

The first and most obvious type of test we performed was a comparison of individual wet (Minolta) vs. dry (Perkin-Elmer) spectrophotometry measurements from the same stratigraphic levels in a core. We chose core intervals that contained hematite, a mineral that can easily be identified by VIS spectrophotometry at concentrations as low as $0.01 \%$ in a carbonate-rich matrix and $0.03 \%$ in a clay-rich matrix (Deaton and Balsam, 1991). Sediments in the top $50 \mathrm{~cm}(0$ $0.5 \mathrm{mbsf}$ ) of Hole 935A appeared especially appropriate because both the core descriptions and the shipboard spectrophotometry (Schneider et al.,1995) indicated that these samples contained hematite. We compared two shipboard measurements on wet core from intervals $155-935 \mathrm{~A}-1 \mathrm{H}-1,10-11 \mathrm{~cm}$ and $45-46 \mathrm{~cm}$, with shore-based measurements on dry Samples 155-935A-1H-1, 4-5 cm and 43-44 $\mathrm{cm}$ (Figs. 3, 4). Although corresponding wet and dry measurements are not from exactly the same stratigraphic levels, they are within 2 to $5 \mathrm{~cm}$ of each other. In addition, the wet measurement at $45-46 \mathrm{~cm}$ was taken just above the top of a more indurated, iron-rich oxidized lamina in interval $155-935 \mathrm{~A}-1 \mathrm{H}-1, \sim 46-46.5 \mathrm{~cm}$.

\section{Results of Comparison}

Examination of the raw reflectance curves (Figs. 3, 4; top) from these measurements indicates that the dry sediments exhibit much higher reflectance than the wet sediments. The wet and dry reflectance values are about the same at $400 \mathrm{~nm}$, but diverge significantly between 400 and $\sim 560 \mathrm{~nm}$. The differences in wet vs. dry values remains constant or increases only slowly between $\sim 560$ and $700 \mathrm{~nm}$. At the red end of the spectrum, the reflectance difference for the wet vs. dry sediments was $10 \%$ to $20 \%$. If only these reflectance curves were used for a comparison, one might conclude that the two spectrophotometers give quite different results. However, first-derivative curves provide a different perspective.

Comparison of first-derivative curves derived from the wet and dry reflectance curves (Figs. 3, 4; bottom) suggests that the shipboard and shore-based measurements are much more similar than indicated by the raw reflectance curves (Figs. 3, 4; top). This similarity is especially obvious in Figure 3 (bottom), where both the shipboard and shore-based curves exhibit the characteristic hematite peak at 555 $\mathrm{nm}$, a shoulder in the peak at $535 \mathrm{~nm}$ indicative of goethite combined 

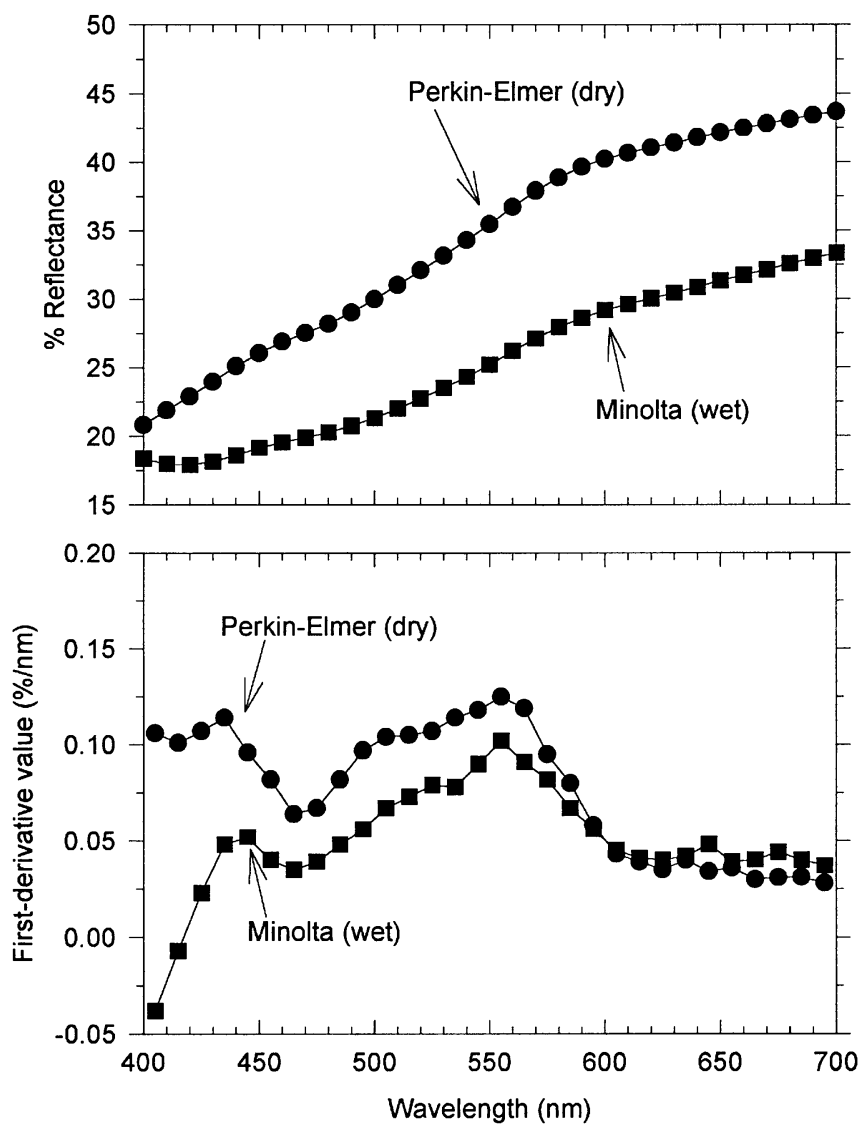

Figure 3. Top: Percent-reflectance curves measured near the top of Core 155935A-1H-1. Interval 155-935A-1H-1, 10-11 cm, (solid squares) was measured on a wet core on board ship using the Minolta CM-2002; whereas Sample 155-935A-1H-1, 5-6 cm, (solid circles) was dried and measured in the laboratory using the Perkin-Elmer Lambda 6. Bottom: First-derivative curves derived from the reflectance curves at the top. Note that although the reflectance curves differ, the first-derivative curves suggest the spectra are similar (see text).

with hematite, and a goethite peak at $435 \mathrm{~nm}$. Although the positions of the peaks in these two curves are identical, the amplitudes of the peaks are slightly smaller for the wet curve (Fig. 3; bottom). This reduction in peak amplitude probably results from the lower reflectance of the wet sediment, thus limiting the rate at which the slope of the reflectance curve can increase. The two curves show substantial divergence between 400 and $445 \mathrm{~nm}$, which, as discussed above, probably can be attributed to the use of Saran Wrap to cover the cores, and the tendency for reflectance values measured with the Minolta instrument to fall off at the violet end of the spectrum.

For the other set of curves (Fig. 4; bottom), the general shape of the curves is also quite similar; however, the peaks from the wet sediment are much more muted. This difference may result from a higher concentration of goethite relative to hematite (as indicated by the height of the $435 \mathrm{~nm}$ peak) in this interval and/or from higher water content in this interval compared to the upper interval (Fig. 3; bottom). In addition, the wet measurement was taken right at the transition to an indurated, iron-rich oxidized lamina in interval 155-935A$1 \mathrm{H}-1, \sim 46-46.5 \mathrm{~cm}$, whereas the dry measurement was $1-2 \mathrm{~cm}$ above the wet measurement. The curves diverge substantially between 400 and $435 \mathrm{~nm}$ (Fig. 4; bottom), presumably for the reasons stated in the previous paragraph.
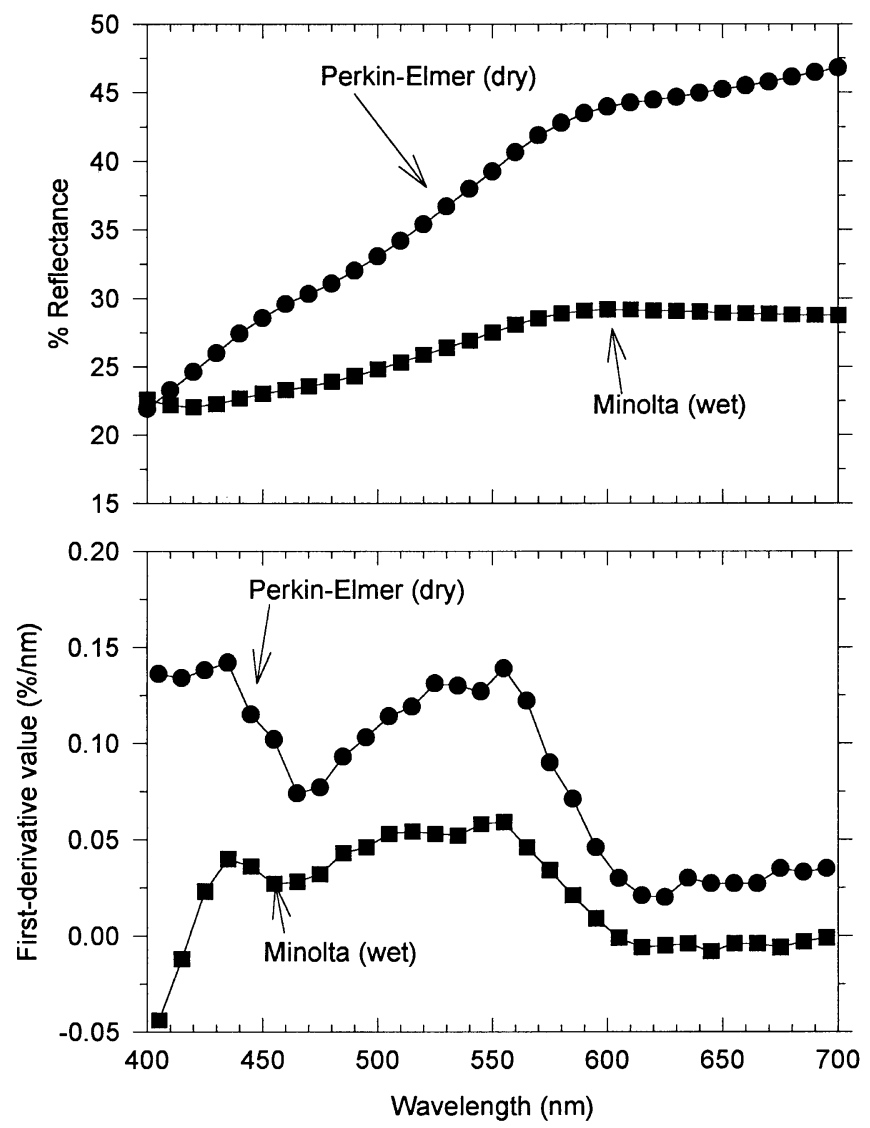

Figure 4. Top: Percent-reflectance curves measured near the top of Section $155-935 \mathrm{~A}-1 \mathrm{H}-1$ from an interval about $30 \mathrm{~cm}$ deeper than the interval measured in Figure 3. Interval 155-935A-1H-1, 45-46 cm, (solid squares) was measured on a wet core aboard ship using the Minolta CM-2002; Sample 155-935A-1H-1, 43-44 cm, (solid circles) was dried and measured in the laboratory using the Perkin-Elmer Lambda 6. Bottom: Unlike the interval measured above (Figure 3, bottom), the first-derivative curves derived from the reflectance curves at this interval are somewhat less similar to each other. In part, this difference may result from the higher concentration of goethite and lower concentration of hematite in this core interval (see text for details).

\section{Conclusion}

Given the differences in the instruments used to measure the spectral data and that wet vs. dry sediments were measured, it is surprising how well the first-derivative curves correlate. If wavelengths $<430$ $\mathrm{nm}$ are eliminated because of instrumental differences and bias caused by Saran Wrap, there is almost a 1:1 correlation between the shapes of the wet and dry curves. Absolute values of the first derivatives derived from wet curves are smaller and produce first-derivative curves in which variations are muted compared to curves from the dry measurements. Experiments in progress, in conjunction with ODP Leg 164 sediments, will more fully delineate the effect of sample wetness.

\section{Comparison of Data Sets Derived from Wet (Shipboard) and Dry (Shore-Based) Measurements}

\section{Construction of Data Sets}

Because of the high degree of correlation observed between individual wet and dry reflectance curves at the two test intervals de- 
scribed above, we proceeded to apply a test that would examine the structure of the data generated by analysis of a large number of reflectance measurements from two comparable data sets from the majority of Leg 155 holes. One data set was obtained aboard ship from wet cores with the Minolta CM-2002. The other set was obtained from measurement of dry, prepared core samples with the Perkin-Elmer shore-based instrument. We applied the analytical technique factor analysis to address the question "Is the variability in the two data sets contained in the same covarying wavelengths?" If the answer to this question turned out to be yes, then the shipboard and shore-based instruments and techniques give comparable results despite all their differences.

Our data set for the shore-based spectral analyses was derived from core samples taken at $\sim 1.5$-m intervals downhole (approximately one sample per section). The shipboard spectral analyses were performed at $40-\mathrm{cm}$ or less intervals (about four per section). In order to construct comparable data sets, we selected only those shipboard spectral analyses that were at or close to our sample depths downhole. We considered a shipboard measurement that was within $20 \mathrm{~cm}$ of a core sample to be at identical depths. In cases where the core sample location was exactly midway between two shipboard measurements, we included both shipboard measurements; otherwise, only the closest shipboard measurement to a core sample was utilized. Shipboard measurements and core samples separated from each other by more than $20 \mathrm{~cm}$ were considered to have no equivalent, and neither was included in the databases. Applying these guidelines to 12 Leg 155 holes, we assembled a shore-based spectral data set of 1458 measurements and a shipboard data set of 1498 measurements. Depending on depth of penetration below seafloor, each hole was represented by 80 to 170 measurements, or about one measurement per section (i.e., 67 samples per core). The shore-based data set contained first-derivative values from 255 to $845 \mathrm{~nm}$ for each sample interval resulting in a matrix of 1458 samples by 60 first-derivative values. In comparison, the shipboard data set contained first-derivative values from 405 to $695 \mathrm{~nm}$, and the assembled matrix was 1498 samples by 30 firstderivative values. Because of the more limited range of the shipboard instrument, we restricted our preliminary analysis of shore-based data to first-derivative values from 405 to $695 \mathrm{~nm}$.

\section{Factor Analytic Results}

Each of the first-derivative data sets was factor analyzed from 405 to $695 \mathrm{~nm}$. The factor analysis was performed with SAS (v 6.04) for personal computers using the principal factors method to extract the factors and a varimax rotation to make interpretation of the factors easier. We used R-mode factor analysis to group the first derivative variables into factors. Factors were interpreted with respect to sediment composition by comparing factor description curves to first-derivative curves (see below). R-mode factor analysis also allowed us to plot the importance (as indicated by factor scores) of each factordetermined sediment component downhole.

The shorter wavelengths $(405-435 \mathrm{~nm})$ in the shipboard data set had low communalities $(<0.7)$ with a reasonable number of factors, that is, these wavelengths were poorly explained by the factor analysis and made further interpretation of the first-derivative data difficult. Therefore, we eliminated these wavelengths from the data set and reanalyzed the data using the first-derivative values from 435 to $695 \mathrm{~nm}$. Subsequent analyses showed that the $695-\mathrm{nm}$ first-derivative value also was not well explained by a reasonable number of factors; hence, we also eliminated the first-derivative values at $695 \mathrm{~nm}$. The final factor analysis of the shipboard data was carried out on first-derivative values from 435 to $685 \mathrm{~nm}$. The low communality values from 405 to $435 \mathrm{~nm}$ and at $695 \mathrm{~nm}$ are undoubtedly related to the introduction of noise, either from the effect of the Saran Wrap on spectra and/or from the limits of resolution of the instrument. Additional testing will be required to determine the exact cause of this noise.

We chose a four-factor solution for the shipboard data, which, prior to rotation, explained $98.94 \%$ of the cumulative variance. These four factors explained $48.73 \%, 33.04 \%, 15.69 \%$, and $1.48 \%$ of the variance, respectively; all remaining factors explained $0.7 \%$ or less of the variance. Using these four factors, all the wavelengths were explained with a communality $>0.7$, and most with a communality $>0.9$. Based on the work of Balsam and Deaton (1991), Deaton and Balsam (1991), and Balsam and Wolhart (1993), we interpret these factors as indicative of hematite and goethite, clay minerals, organic matter, and carbonate.

For the shore-based data set, we used only the first-derivative values from 405 to $695 \mathrm{~nm}$, so that our results would be comparable to those from the data set. Unlike the shipboard data set, wavelength communalities for the shore-based data were high; all wavelengths exceed 0.87 . The shore-based data set required seven factors to explain $98.71 \%$ of the cumulative variance, and each of these seven factors explained more than $1 \%$ of the variance. This observation suggests that the shore-based data are more sensitive to subtle variations in the spectra. Individual factors, however, are comparable when factor-loading curves are compared (Fig. 5). Factor loadings indicate how important each wavelength is in a factor. When factor loadings are plotted as a function of wavelength, they produce a factor-pattern curve. Comparison of shore-based and shipboard factor-pattern curves shows that Factor 1-shipboard corresponds to Factor 2-shorebased, Factor 2-shipboard corresponds to Factor 3-shore-based, Factor 3-shipboard to Factor 1-shore-based and Factor 4-shipboard to Factor 6-shore-based (Fig. 5). Individual shore-based factors explain $57.57 \%, 24.03 \%, 8.39 \%$, and $1.63 \%$ of the variance, respectively.

The results of this comparison of the shore-based and shipboard data are encouraging. Although these data sets were generated from wet and dry samples with different instruments and different surface preparations, the four factors identified in the shipboard data set are also present in the shore-based data set (Fig. 5). Although the factors differ in their relative importance in the data sets (i.e., explain different amounts of variance), the overall shapes of the factor patterns are similar, which indicates that the same sediment components are being extracted from the wet and dry spectra. The observation that the matching factors do not explain the same amount of variance is not surprising. These differences probably result from measuring wet vs. dry samples, the use of Saran Wrap, and differences in instrumentation.

This comparison of data sets indicates that the answer to our question "Is the variability in the two data sets contained in the same covarying wavelengths?" is clearly yes. However, this answer must be tempered by the observation that the shore-based spectral analysis provided more subtle spectral details, as is indicated by the larger number of factors extracted to explain the same amount of variance. Our study does not indicate whether the increased sensitivity of the shore-based analysis results from differences in wet vs. dry samples, types of instrumentation, or some other cause. Finally, we point out that all major factors of the shipboard data set are present in the shore-based data set, which suggests that for these samples, oxidation did not appreciably alter the spectra.

\section{DETERMINING THE COMPOSITION OF LEG 155 SEDIMENT FROM SPECTRAL ANALYSIS}

The shore-based data set was utilized to illustrate the value of reflectance spectra for interpreting the composition of marine sediments. This data set was chosen for a number of reasons. First, it appears to be more sensitive to subtle variations in spectra. Considering that most of the sediments from the Amazon Fan are very dark in color, subtle spectral changes may be important for interpreting compositional changes. Second, the added wavelength range of the shorebased spectrophotometer potentially could assist in distinguishing between various sediment components. Third, the spectral response of the shore-based spectrophotometer has been determined for a wide variety of minerals and other sediment components using dried and ground samples (see for example Barranco et al., 1989; Balsam and Deaton, 1991; Deaton and Balsam, 1991; Balsam and Wolhart, 1993). Similar determinations would have to be made with the Mi- 

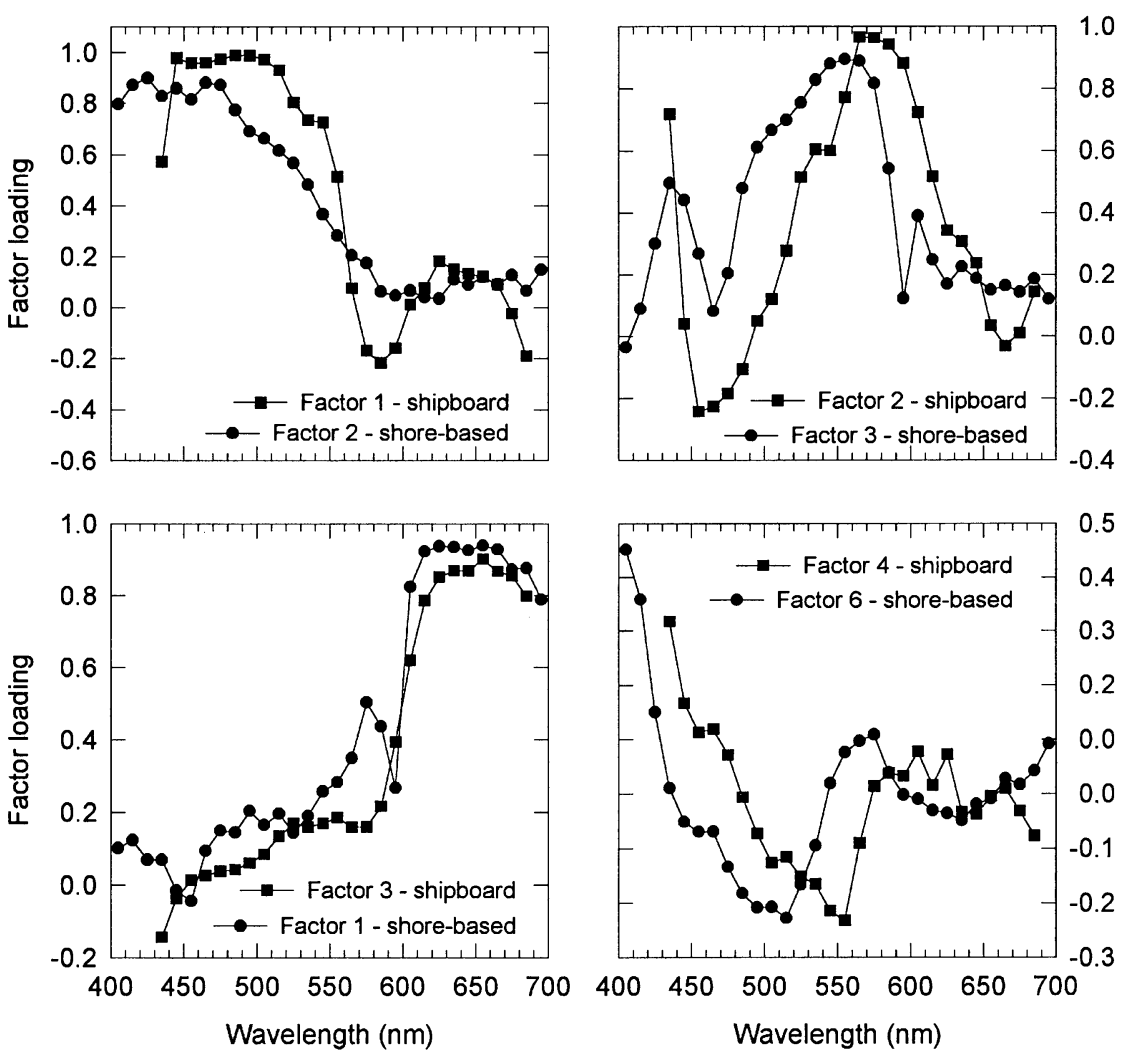

Figure 5. Comparison of factor-pattern curves for shipboard (Minolta; solid squares) and shore-based (Perkin-Elmer; solid circles) spectrophotometers. Factors are based on analysis of a data set from shipboard measurements and a comparable data set from shorebased samples. Both data sets represent all Leg 155 holes subjected to spectrophotometric analysis (see text). The shipboard and shore-based factors are similar, suggesting that, despite differences in sample preparation, core wetness, instrument type and operation, the Minolta instrument produces data that are generally equivalent to the Perkin-Elmer spectrophotometer. nolta shipboard instrument on wet core surfaces before the shipboard data set could be used for detailed interpretation of the spectra of various sediment components. We are not aware of any studies to date that used the Minolta instrument to analyze samples with known concentrations of different sediment components. Such analyses must be carried out both on wet and dry samples to determine the gain or loss of information from varying analytical conditions. Nevertheless, the correspondence of shore-based and shipboard factors is very encouraging and suggests that such ground-truth studies with the Minolta instrument will produce good results. However, such studies were beyond the scope of the present study.

The entire wavelength range of the shore-based data set was utilized, that is, for each of the 1458 samples, the 60 first-derivative values from 255 to $845 \mathrm{~nm}$ were analyzed. This data set was factor analyzed using SAS, and then wavelengths with low communalities were deleted from further analyses. We settled on a data set that included first-derivative values from 335 to $725 \mathrm{~nm}$ because first-derivative values less than $335 \mathrm{~nm}$ and greater than $725 \mathrm{~nm}$ added mainly noise to the factor analysis. Recent work (Balsam and Deaton, 1996) indicates that wavelengths in the NIR, especially from 740 to $850 \mathrm{~nm}$, are noisy. Although NUV wavelengths shorter than $330 \mathrm{~nm}$ appear to add mainly noise to our Amazon Fan factor analyses, these short wavelengths have proved valuable in studies of other regions (Balsam and Deaton, 1996). After factor analyzing first-derivative values from 335 to $725 \mathrm{~nm}$, we decided on a six-factor solution because $98.5 \%$ of the cumulative variance was explained, and all the factors explained at least $1 \%$ of the variance. Further, the factor-pattern curves (Fig. 6) for the six factors could be related to known sediment components.

\section{Interpreting Factor-Pattern Curves and Relating Factors to Sediment Composition}

Factor-pattern curves are interpreted by comparison to the variables they were derived from, in this case, first-derivative curves. Because peaks in first-derivative values are related to sediment composition (Balsam and Deaton, 1991; Deaton and Balsam, 1991), factor- pattern curves are interpreted by relating them to first-derivative curves from samples with a known composition. A good example of how factor pattern curves are interpreted is illustrated by the comparison of shore-based Factor 3, VIS wavelength data set (Fig. 5) with the first-derivative curve of a sample that contains a known mixture of hematite and goethite (Fig. 7). Hematite has a single first-derivative peak between $555 \mathrm{~nm}$ and $575 \mathrm{~nm}$, depending on concentration; goethite has two first-derivative peaks, one at $435 \mathrm{~nm}$ and the other at $535 \mathrm{~nm}$ (Deaton and Balsam, 1991). When combined, the goethite tends to broaden the hematite peak, and the 535-nm goethite peak produces a shoulder on the broadened hematite peak; the 435-nm peak remains unchanged. However, hematite has a much stronger spectral signal than goethite, and a small quantity of hematite will overwhelm the goethite. As shown by the relative heights of the peaks on Factor 3-shore-based compared to the known sample (Fig. 7), Factor 3-shore-based is rich in goethite relative to hematite. Examples of other minerals and sediment components are presented in Balsam and Deaton (1991) and Balsam and Wolhart (1993).

It is important to keep in mind that the detection limit of spectrally identified sediment components may differ from other, commonly used methods of identification such as X-ray diffraction (XRD). For example, Deaton and Balsam (1991) demonstrated that in a white matrix, hematite can be identified at concentrations $>0.01 \%$ by weight, whereas with XRD, the detection limit is $\sim 0.2 \%$. It is also important to remember that, similar to XRD, the detection limit for a specific sediment component using NUV/VIS/NIR spectra is subject to a "matrix effect."

Based on qualitative visual comparison to first-derivative spectral curves of mineral "knowns," the factor pattern curves from the shorebased 335-725 nm database (Fig. 6) are interpretable in terms of sediment composition. Factor 1 appears to be organic matter that causes absorption in shorter wavelengths of the VIS and in the NUV (Balsam and Wolhart, 1993). Factors 2 and 5 are clearly related to iron oxides and oxyhydroxides; Factor 2 is goethite, and Factor 5 is hematite (Deaton and Balsam, 1991). Factor 3 appears to be related to a combination of clay minerals, most likely illite and montmorillonite (Balsam and Deaton, 1991). Factor 4 matches the first-derivative 

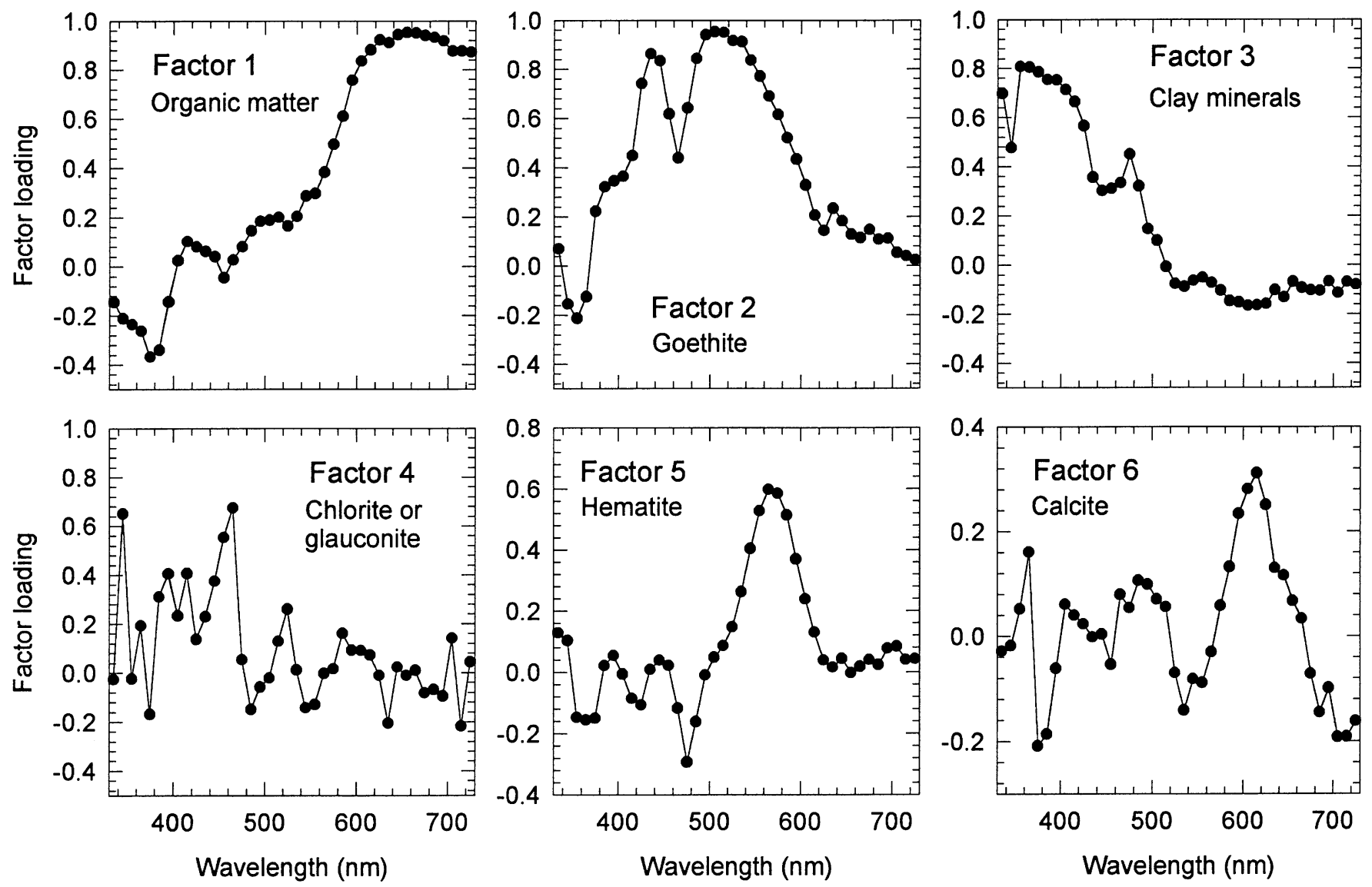

Figure 6. Factor-pattern curves from analysis of the shore-based spectrophotometer data set. The six-factor solution presented here explains $98.5 \%$ of the cumulative variance, and all the factors explained at least $1 \%$ of the variance (see text).

curve for the clay mineral chlorite (Balsam and Deaton, 1991). However, we can't rule out that Factor 4 is related to glauconite, another green mineral, which we have yet to analyze. Factor 6 appears to be calcite. Although calcite is white and has a uniformly high reflectance value throughout the VIS, Balsam and Deaton (1991) and Balsam and Wolhart (1993) found that a first-derivative peak at about $605 \mathrm{~nm}$, a location where no other minerals have peaks, was related to calcite concentration.

\section{Downcore Variations in the Factors}

Factor analysis is useful not only because factor-pattern curves can be used to determine where the variability in the data lies, but also because the importance of each factor can be determined in each sample. Factor scores, which indicate the importance of factors in a sample (see above), provide a temporal record of changes in a factor when plotted downhole (e.g., Fig. 8). If a factor has been related to a sediment component or combination of sediment components, then a factor-score plot provides a semiquantitative estimate of changes in those components. The value of a factor score is increased by the fact that it can be estimated for samples that have not been included in the original factor data set.

Our interpretation of factor-score plots (Fig. 8) will be limited to obvious changes and general trends because our analysis of the factor patterns is still somewhat cursory. As noted above, interpretation of the factor patterns is hindered by a number of problems. These problems include limits of resolution of the spectral technique for various minerals (or lack of knowledge of such limits), spectral interaction between minerals (the "matrix effect"), and the mineralogically com- plex nature of marine sediments. In addition, for the purposes of determining mineralogy, factor analysis has a serious weakness: it groups together wavelengths that covary. This means that if two minerals occur together, they will be grouped into the same factor. Our Factor 3 (Fig. 6), illite and montmorillonite, probably results from the co-occurrence of these two minerals.

We can check our interpretation of several factors by comparison to shipboard compositional and mineralogical data (Flood, Piper, Klaus, et al., 1995). Specifically, we can contrast total organic carbon (TOC) to Factor 1, variations in XRD-determined clay minerals to Factor 3, and variations in measured calcium carbonate content to Factor 6 (Fig. 8; Table 2, on CD-ROM, back pocket, this volume).

\section{Factor 1 and TOC}

In general, the contrast between Factor 1 and TOC measured on Leg 155 (Flood, Piper, Klaus, et al., 1995) is good. Discrepancies probably result from the way in which NUV/VIS/NIR spectra respond to organic materials. Organic material becomes darker with age. Young organic material has an absorption band that extends from the NUV into violet wavelengths of the VIS. This absorption band extends progressively farther through the VIS as organic matter becomes older and more refractory (Balsam and Wolhart, 1993). Highly refractory organic matter (e.g., coal) may be difficult to distinguish with NUV/VIS/NIR spectra. The pattern curve for Factor 1 (Fig. 6) suggests that this factor is responding mainly to less refractory (young) organic matter, whereas the shipboard TOC data truly represent TOC (Shipboard Scientific Party, 1995), including both young material and older, more refractory material. Because Leg 155 


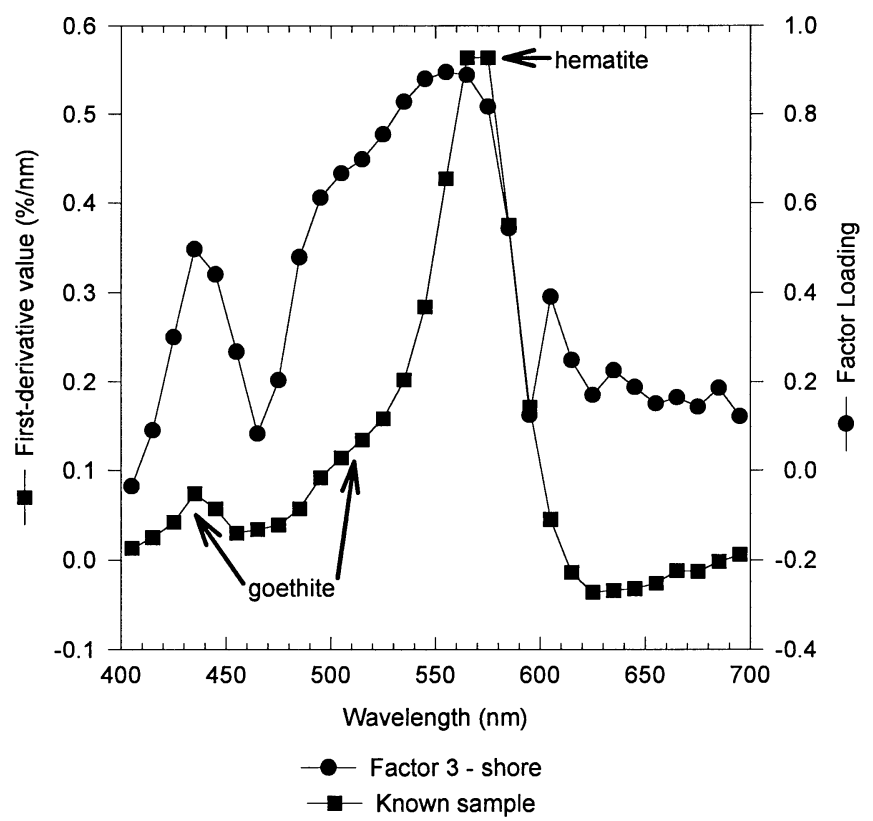

Figure 7. Example of interpretation of a factor-pattern curve (shore-based Factor 3; VIS wavelength 400-700 nm; Fig. 5) by comparison to the firstderivative curve from a known sample, which contains $1 \%$ hematite, $2 \%$ goethite, $60 \%$ quartz, $30 \%$ chlorite, and $7 \%$ calcite.

holes were drilled in areas of extremely high terrigenous sediment accumulation, the presence of refractory organic matter is to be anticipated. Despite the possibility that refractory organic matter is present and that there are relatively few downhole TOC shipboard analyses, the comparison between Factor 1 and TOC for all the holes is surprisingly good.

In most of the holes, the overbank deposits of the channel-levee systems show fairly constant Factor 1 scores downhole; however, the younger hemipelagic sediments that blanket the channel-levee systems show much more variable factor scores downhole (Fig. 8, Sites 932, $933,938,939,940$, and 942). This relationship is especially evident in Hole 942A where lithologic Units I through V (0- 75 mbsf) are more hemipelagic dominated and apparently reflect fluctuations in sediment input controlled by glacio-eustatic sea-level fluctuations (see oxygen isotopes curve, Fig. 8, Site 942; and Showers et al., this volume). Lithic Unit VI below is thick levee overbank deposits and shows much more constant Factor 1 scores than lithologic Units I to V above. Factor 1 scores from mass-transport deposits (Fig. 8, Sites 933, 935, 936, 941, and 944) and HARP units (Fig. 8, Sites 935 and 936) also show quite a bit of internal variability when compared to the levee overbank deposits.

\section{Factor 3 and Clay Mineralogy}

The comparison of Factor 3 to XRD-determined clay minerals in Leg 155 holes is uncertain for several reasons. First, Factor 3 appears to be a combination of several clay minerals including illite and montmorillonite. Second, shipboard XRD determinations did not distinguish mica from illite, and the data were presented as mica and illite combined (Shipboard Scientific Party, 1995). Third, it is difficult to quantify mineral content from XRD data because of the "matrix effect." As a result, the shipboard XRD data for clay-mineral samples were normalized to the kaolinite peak height-making variations in other clay minerals dependent on changes in kaolinite. Given these limitations, we can only conclude that shipboard XRD determinations of clay mineralogy do not conflict with our interpretation of Factor 3 as illite and montmorillonite. It is interesting to note that the red/blue color-reflectance ratio determined for shipboard spectra cor- responds best to our Factor 3 and may, therefore, represent a combination of clay minerals.

\section{Factor 6 and Carbonate Content}

We used the vacuum-gasometric technique of Jones and Kaiteris (1983) to determine weight percent calcium carbonate content of a majority of the same core samples that we analyzed with the PerkinElmer spectrophotometer (Fig. 8; Table 2, see CD-ROM). This technique, as applied in our laboratory, has an accuracy of $\pm 1 \%$. Carbonate curves for all analyzed holes exhibit a carbonate high $(25 \%-40 \%)$ at the very top of each hole; carbonate values then rapidly fall off downhole to $1 \%$ or less for the remainder of the hole (Fig. 8). Additional carbonate highs rarely occur downhole but, when present, are relatively thin beds (Fig. 8) (see also Mikkelsen et al.; Maslin and Mikkelsen; Piper et. al, Chapter 39; and Showers et al., all this volume). In contrast, Hole 942A exhibits several carbonate spikes in the upper $75 \mathrm{mbsf}$ that appear to correlate with isotope Stages 5E, 5C, 5A, and 3 (Fig. 8, Site 942; see also Showers et al., this volume).

The veracity of our interpretation that Factor 6 is controlled by carbonate content is evident from the comparison of the factor score with the carbonate curves (Fig. 8). Almost every carbonate high at the top of each hole correlates with a peak in Factor 6. In addition, for Holes 938A, 941A, and 942A (Fig. 8), there is a direct correlation between changes in carbonate content and Factor 6 . In three other holes, 932A, 936A, and 940A, Factor 6 scores and carbonate content do not appear to show a consistent correlation. In Hole 940A, the carbonate high at the top of the hole does not appear to produce a corresponding change in Factor 6 (Fig. 8, Site 940); however, the redox boundary, which in other holes commonly contains iron-rich crusts and produces high factor scores indicative of low carbonate content, is near the top of this hole, and the interval sampled for spectrophotometry and carbonate (interval 155-946A-1H-1, 7-8 cm; Table 2 on CD-ROM) is in this redox boundary zone between rust-colored iron-rich crusts (intervals 1H-1, 6-7 cm and 10-13 cm; Flood, Piper, Klaus, et al., 1995). In Hole 932A, a carbonate high at about $45 \mathrm{mbsf}$ is matched by a prominent valley in the Factor 6 curve (Fig. 8, Site 932), whereas in Hole 936A, a carbonate peak at about $101 \mathrm{mbsf}$ has no corresponding Factor 6 peak (Fig. 8). For the remainder of the holes, either the carbonate content is consistently low and is matched by values of Factor 6 that show very little fluctuation, or our carbonate analyses were restricted only to top portions of holes in which Factor 6 exhibits changes farther downhole. Clearly the spectral technique is not a perfect predictor of carbonate content, but given the generally low carbonate values prevalent in Amazon Fan sediments because of extremely high terrigenous dilution (Fig. 8), Factor 6 is remarkably reliable at predicting carbonate highs.

\section{Temporal Changes in Factors}

The most obvious change in the factor-score plots occurs in the top few meters of each hole where each factor score shows large fluctuations in this thin interval. Generally, these fluctuations are from high values in the shallowest samples to low values slightly deeper, and then to back to higher values downhole. These rapid fluctuations appear to result from the combined effect of the presence of a redox layer and changing sediment characteristics related to glacio-eustatic sea-level rise at the beginning of the Holocene. Piston-core studies of the Amazon Fan and the adjacent Guiana Basin prior to Leg 155 revealed that latest Pleistocene-age sediments are gray muds and interbedded silt/sands, commonly stained by hydrotroilite. These sediments are overlain by a thin (generally $1 \mathrm{~m}$ or less) layer of tan to brownish pelagic calcareous clay to foraminifer ooze of predominantly Holocene age (Damuth, 1977). Although slightly diachronous across the Guiana Basin, this redox boundary between the brown oxidized sediments above and the gray reduced sediments below approximately marks the Holocene/Pleistocene boundary and is com- 


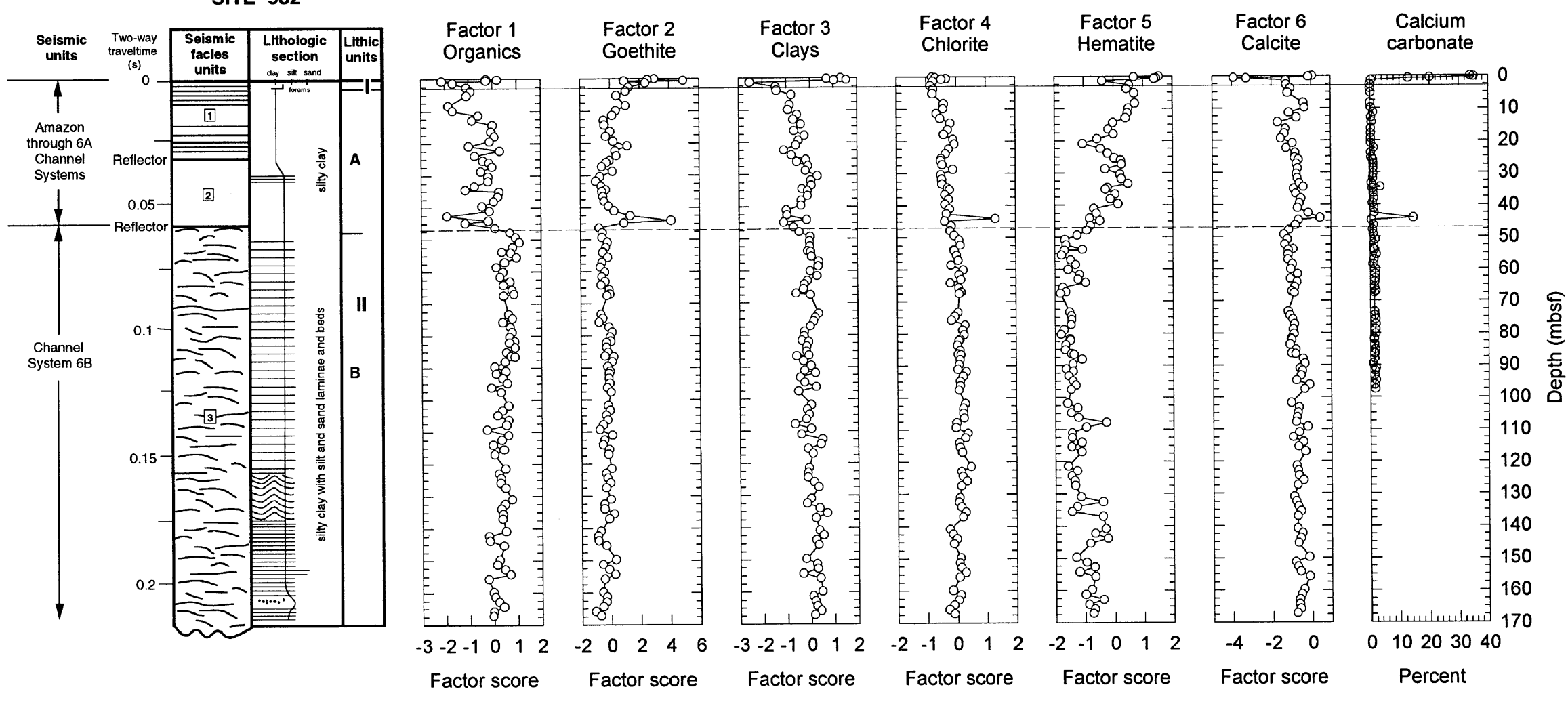

Figure 8. Downhole variations in factor scores for the six factors (Fig. 6) derived from land-based spectral analysis of samples from 12 Leg 155 holes. The oxygen-isotope curve for Hole $942 \mathrm{~A}$ is from Showers et al., this volume. Weight percent calcium carbonate as determined by the vacuum-gasometric technique (see text) is also plotted for some or all samples down each hole (see Table 2 on CD-ROM, for sample locations and carbonate values). The schematic diagram to the left of each set of plots shows composite lithology, lithologic units, subunits, seismic-facies units, and seismic units of the Amazon Fan (e.g., Amazon Channel System) at each drill site (see "Explanatory Notes" and appropriate site chapters in Flood, Piper, Klaus, et al., 1995, for explanation of symbols and detailed descriptions of lithology and seismic facies). Horizontal lines through factor-score and carbonate plots delineate lithologic unit (solid lines) and subunit (dashed lines) boundaries. 


\section{SITE 933}
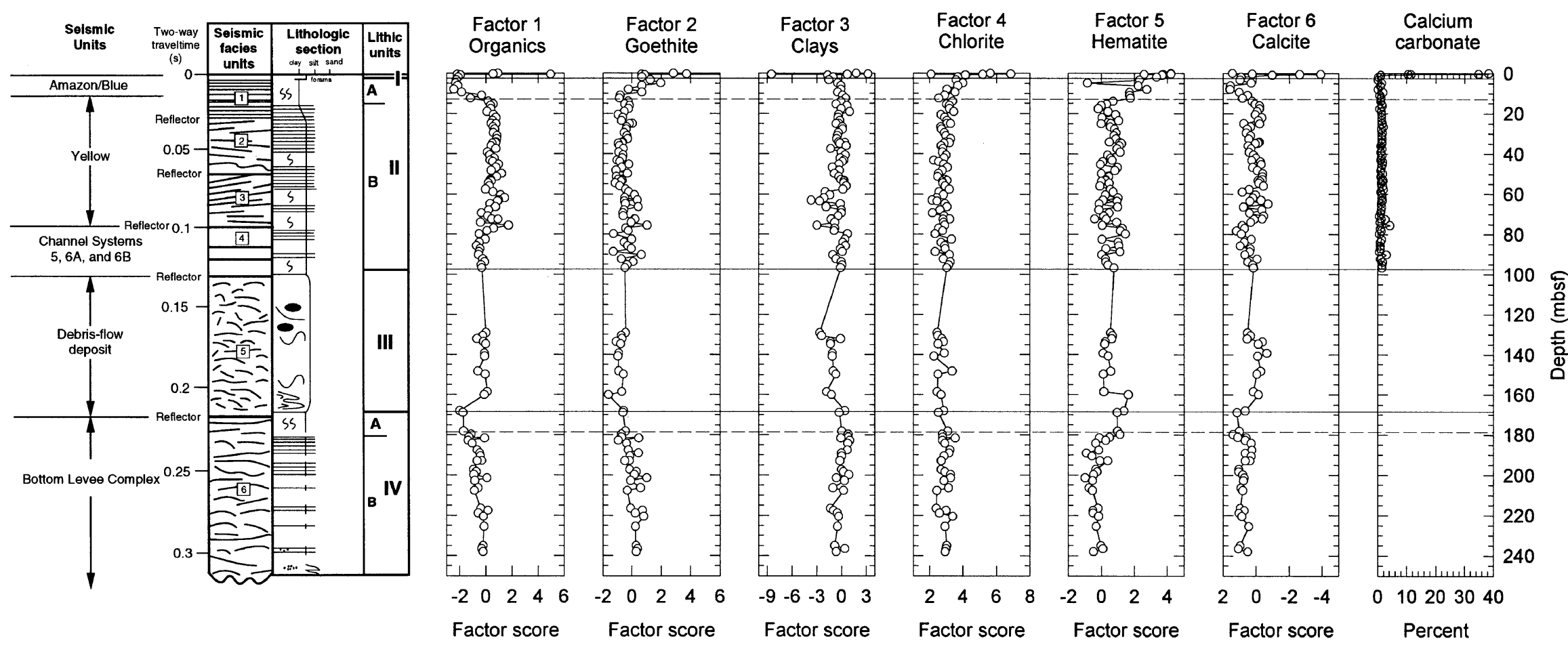

Figure 8 (continued).

Hole 155-933A 

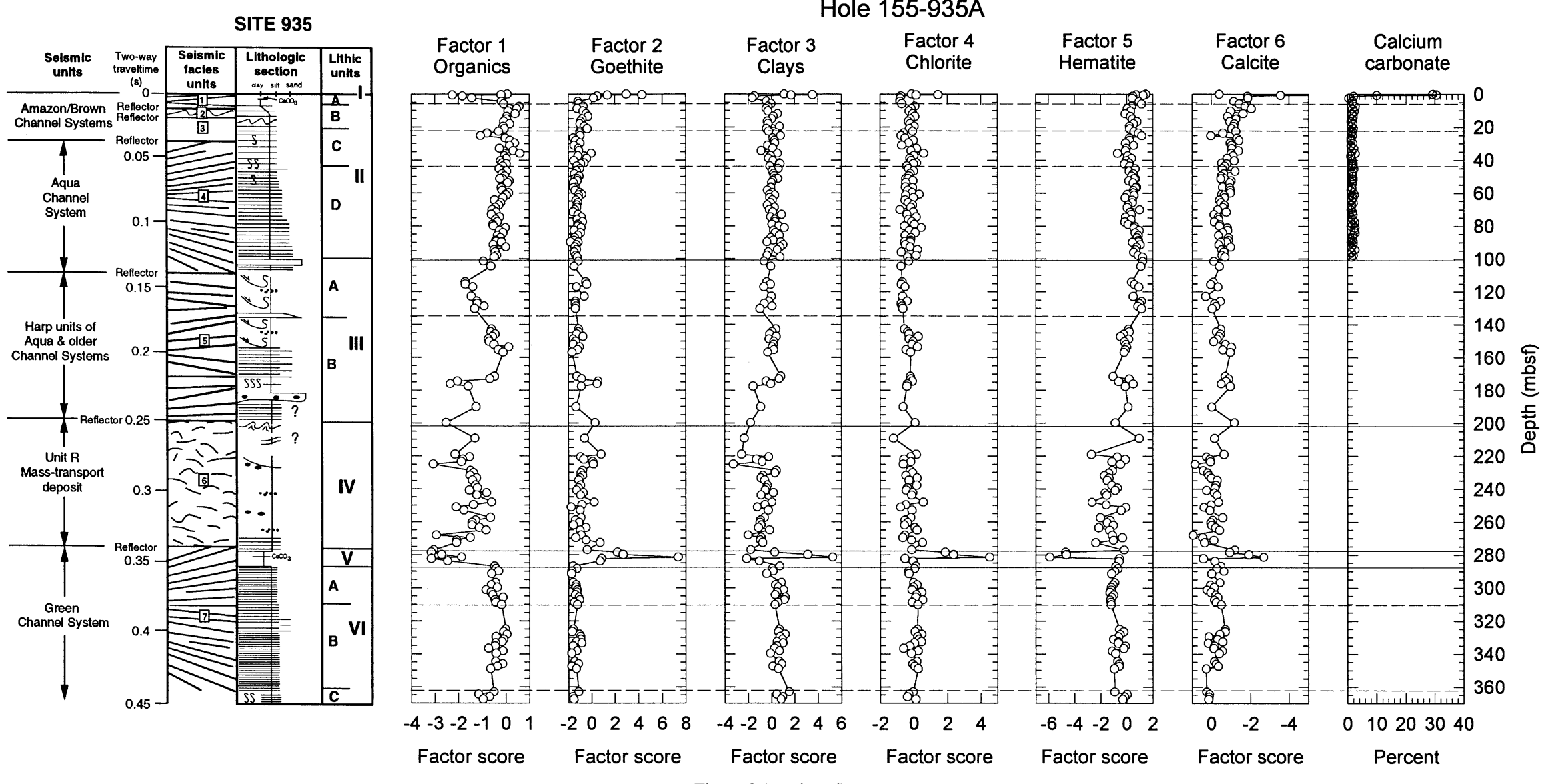

Hole 155-935A 

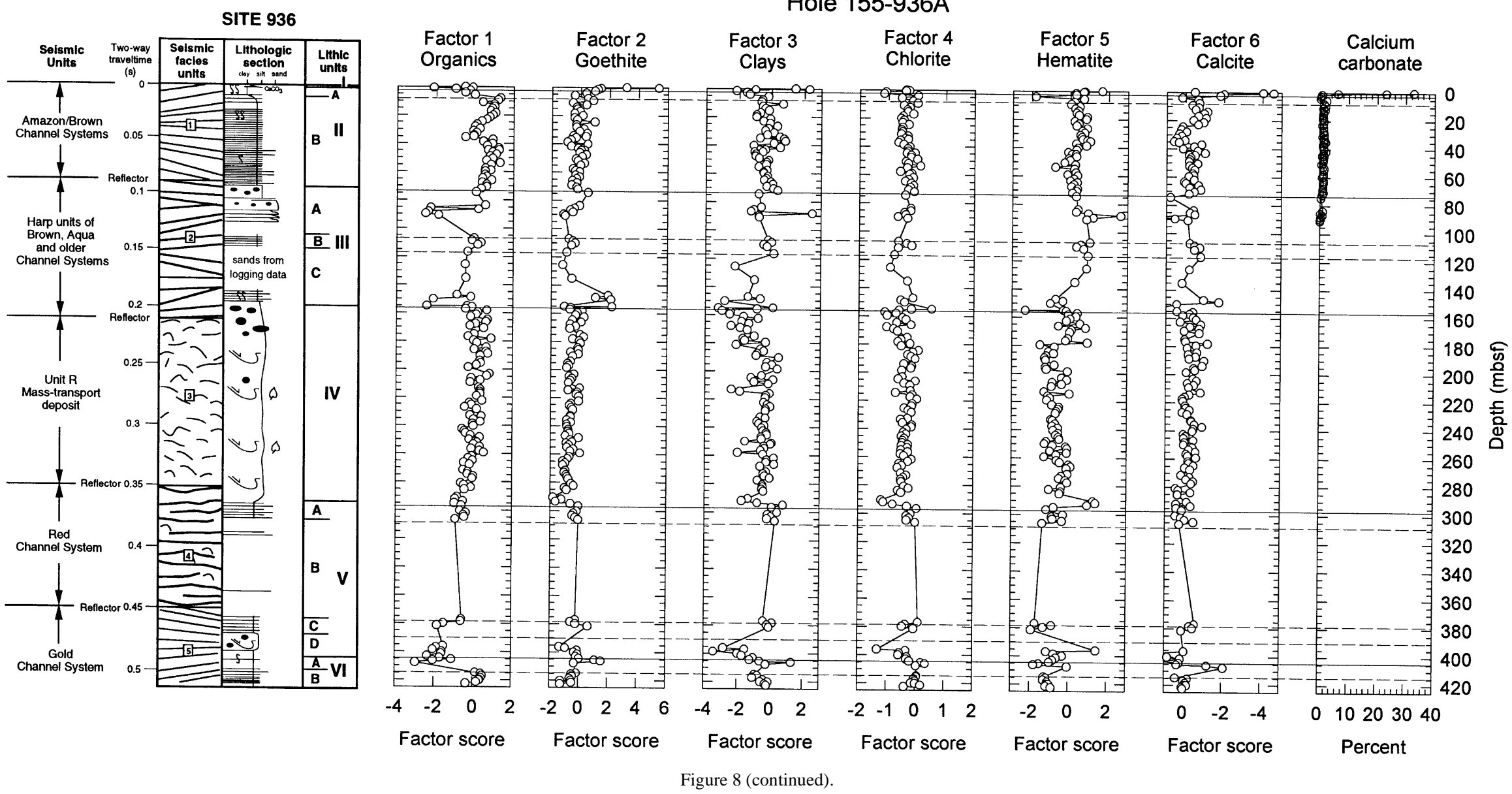


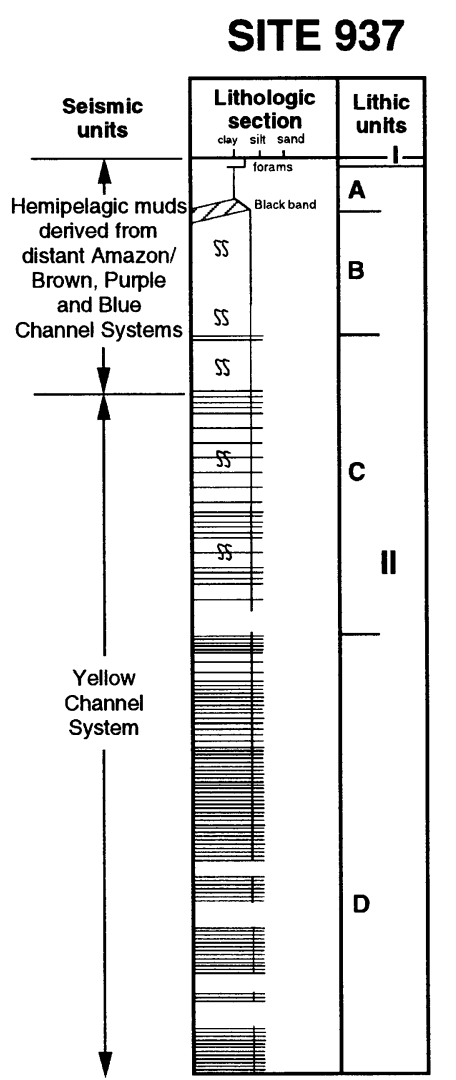

Hole 155-937B

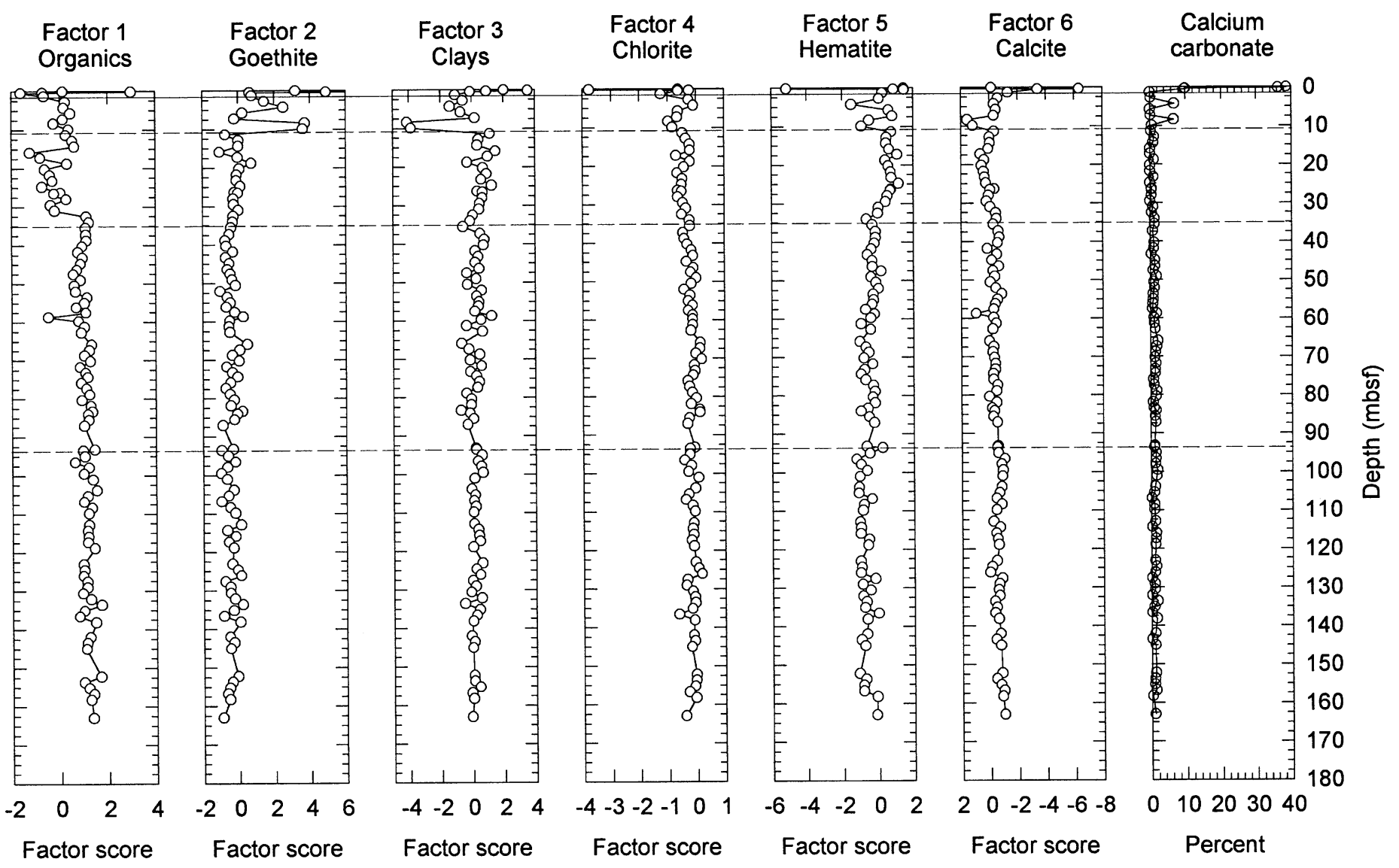

Figure 8 (continued) 

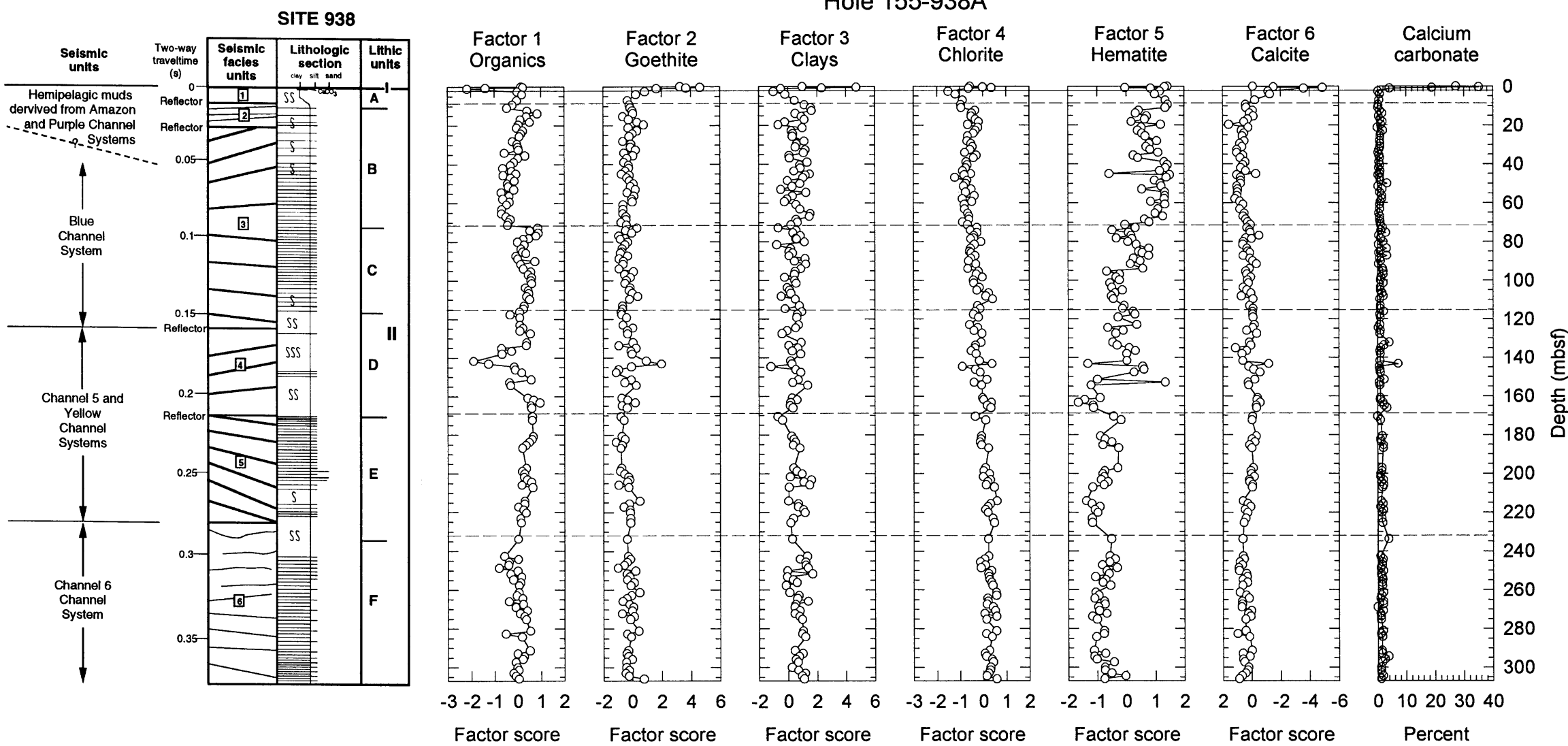

Figure 8 (continued) 
Hole 155-939B
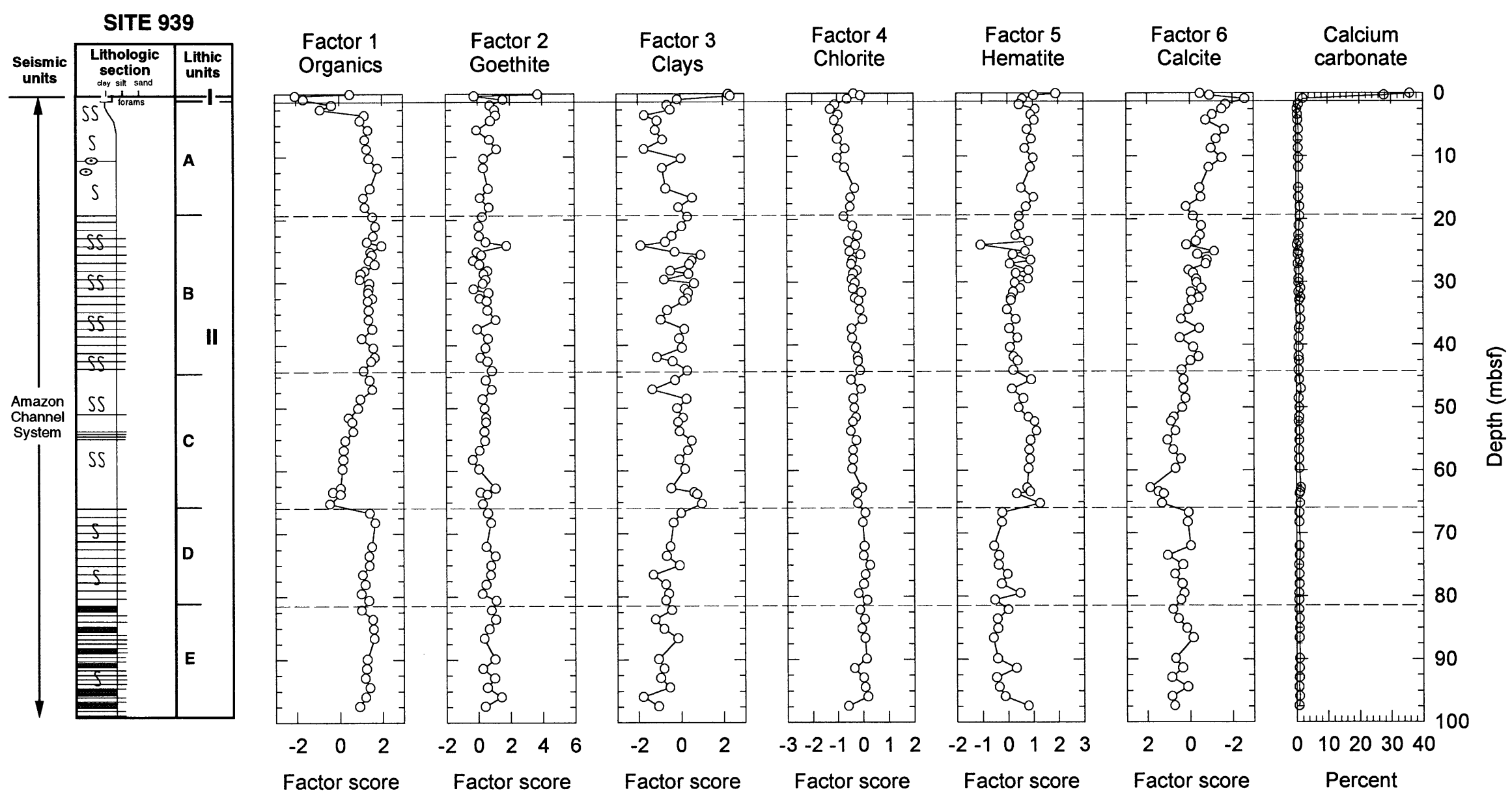

Figure 8 (continued) 

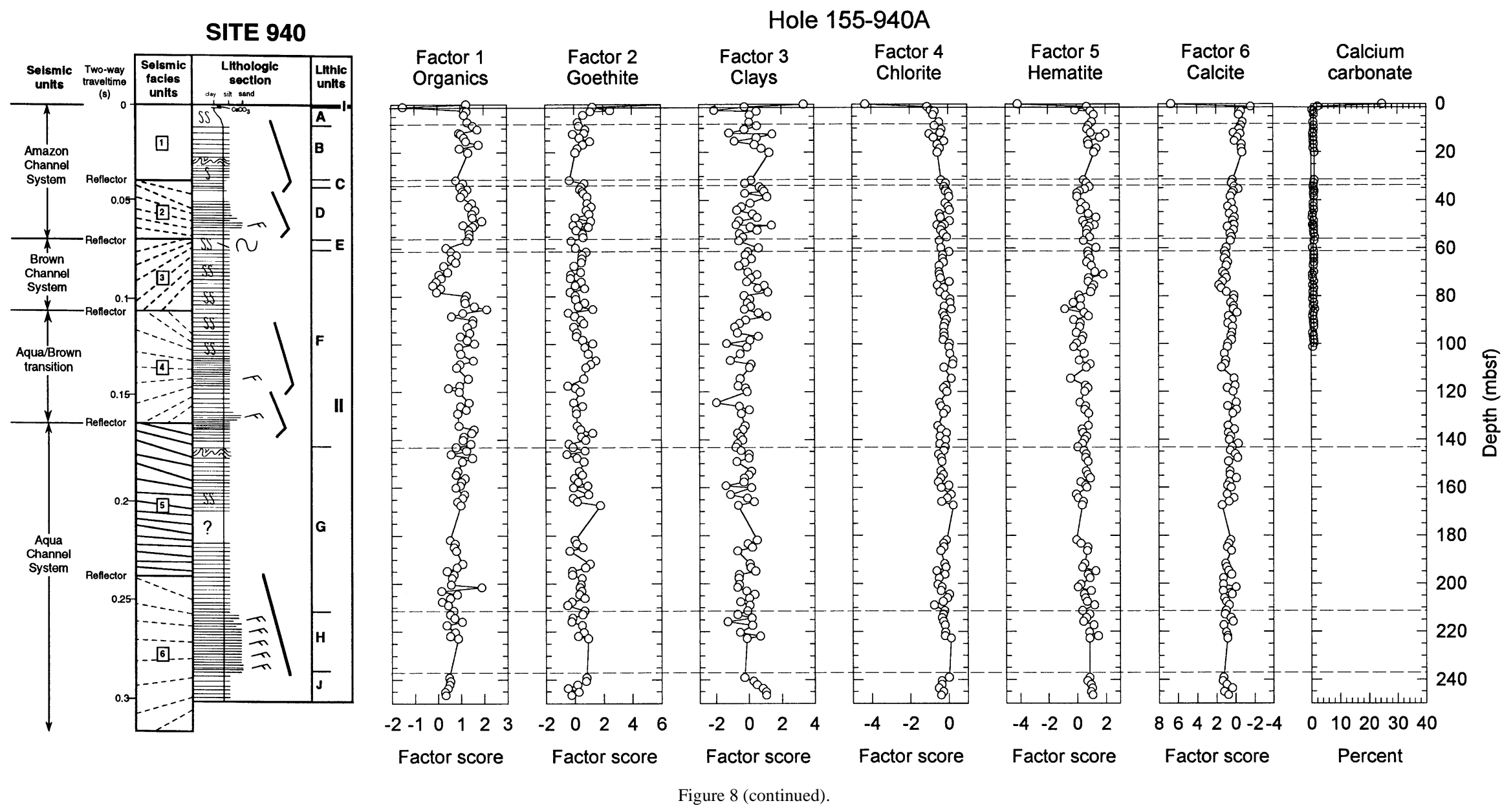
Hole 155-941A
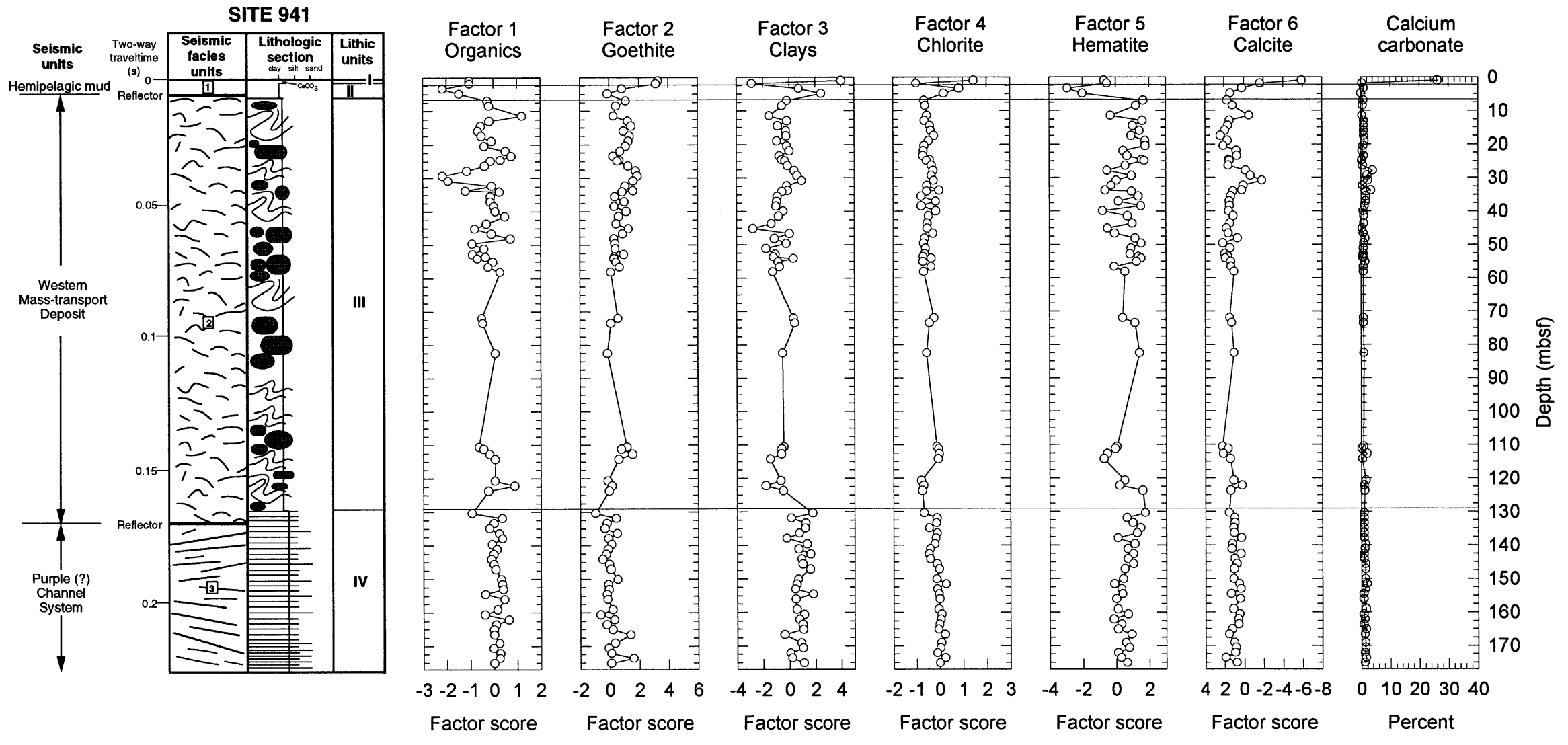

Figure 8 (continued). 


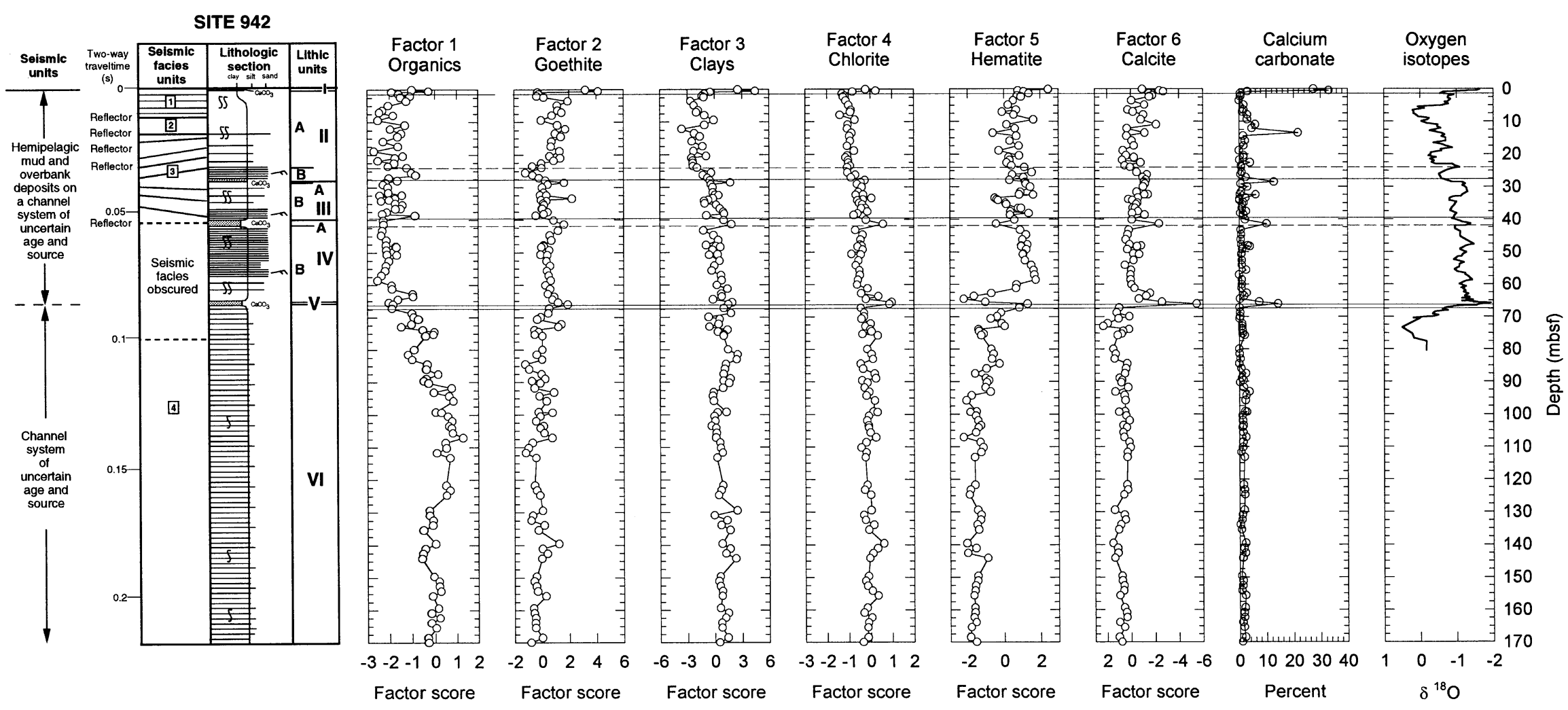

Figure 8 (continued). 

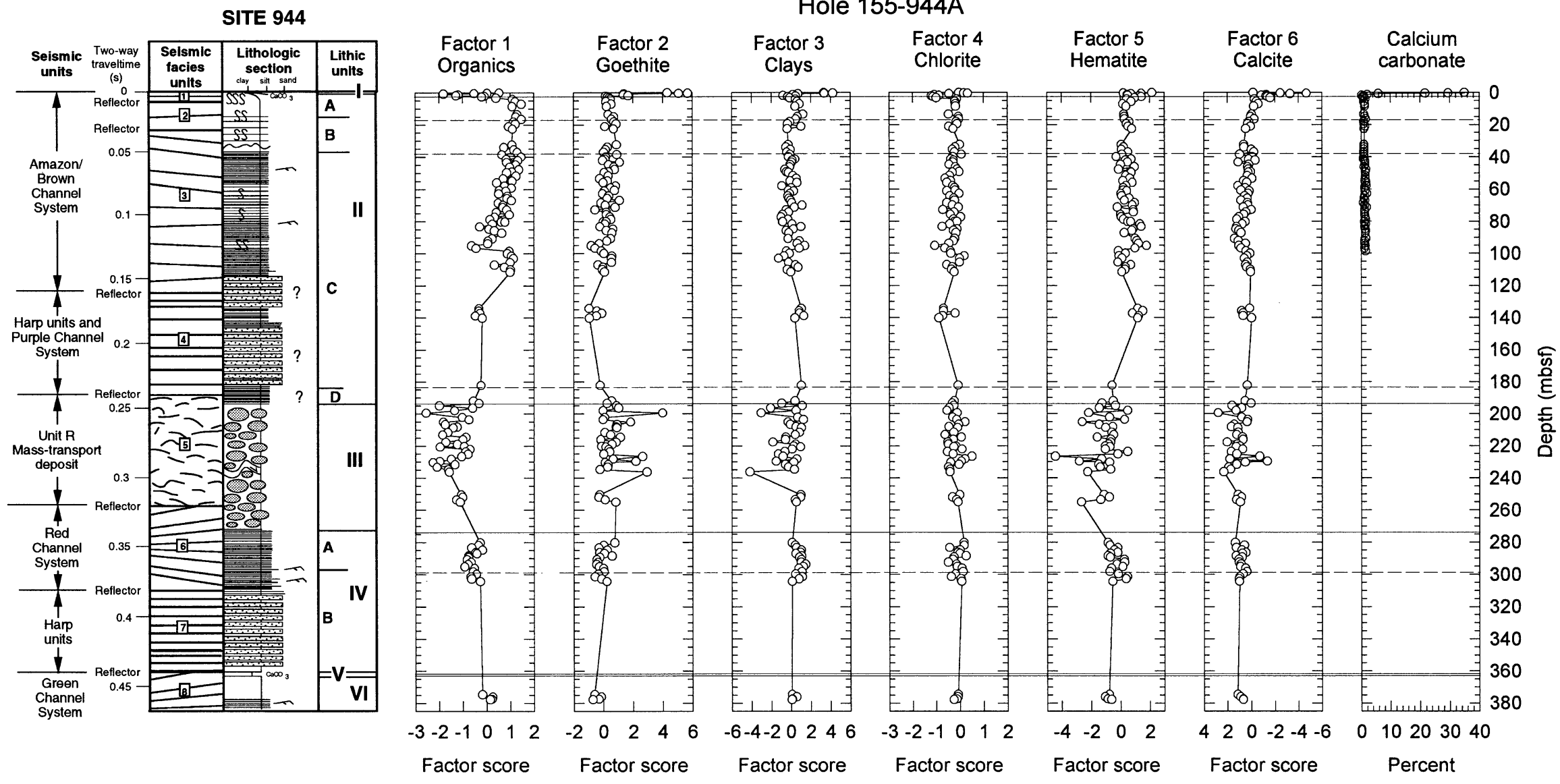

Figure 8 (continued). 
SITE 946

Hole 155-946A
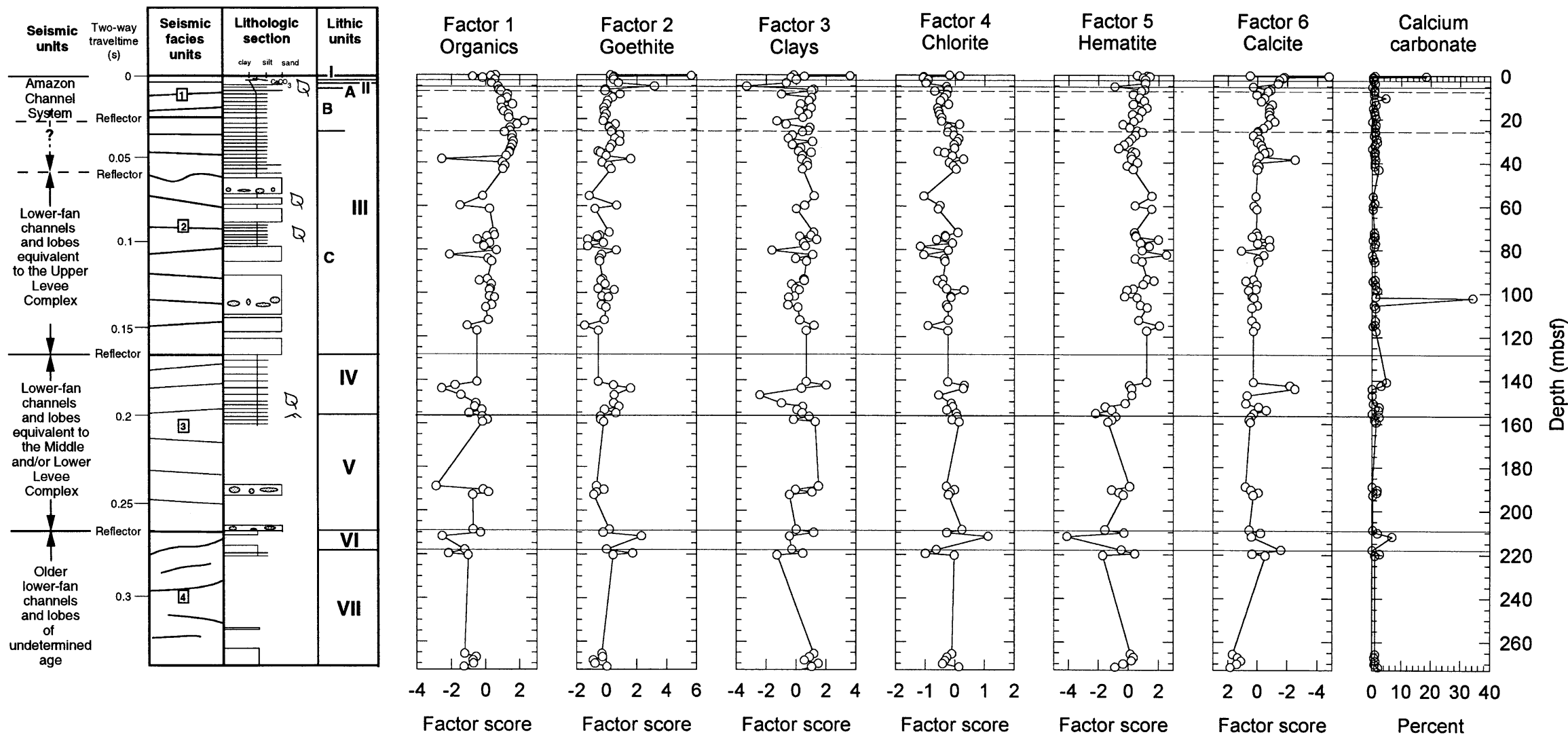

Figure 8 (continued). 
monly indicated by the occurrence of a thin $(<5 \mathrm{~cm})$, diagenetic, ironrich crust (Damuth and Fairbridge, 1970; McGeary and Damuth, 1973; Richardson, 1974; Damuth and Kumar, 1975; Damuth, 1977; Damuth et al; 1988). These same stratigraphic relationships occur in the top $2 \mathrm{~m}$ of each of the Leg 155 holes (Flood, Piper, Klaus, et al., 1995).

Most of the analytical results of pore water chemistry including salinity, $\mathrm{pH}$, alkalinity, $\mathrm{Ca}^{+}, \mathrm{SO}_{4}{ }^{2-}, \mathrm{NH}_{4}{ }^{+}, \mathrm{HPO}_{4}{ }^{2-}, \mathrm{K}^{+}, \mathrm{Na}^{+}, \mathrm{Fe}^{2+}$, and $\mathrm{Mn}^{2+}$, while indicating a change in the top 10-20 m, are too widely spaced to be correlated to spectral variations noted above (Flood, Piper, Klaus, et al., 1995). The change from carbonate-rich sediments at the top of the hole to sediments rich in the dark iron monosulfide hydrotroilite $\left(\mathrm{FeS} \cdot \mathrm{nH}_{2} \mathrm{O}\right)$ just below is probably responsible for most of the rapid variation in the factor-score plots (Fig. 8). Superimposed on these changes are variations in sediment composition that result from the Holocene transgression. During the late Wisconsin lowstand, the Amazon River debouched its sediment directly into the head of the Amazon Submarine Canyon at the continental shelf edge and allowed deposition of large amounts of gray terrigenous sediment to be deposited by turbidity currents and related flows across the Amazon Fan. In contrast, the Holocene transgression forced the locus of river sedimentation to the innermost shelf and prevented most terrigenous sediment from reaching the fan during the Holocene. The fan became essentially inactive, and only the thin layer of tan to brownish pelagic calcareous clay to foraminifer ooze accumulated (Damuth and Kumar, 1975; Damuth, 1977; Flood, Piper, Klaus, et al., 1995). The shipboard spectral data presented as the red/ blue reflectance ratio exhibit similar high-frequency variations in the top 5-10 $\mathrm{m}$ in most of the holes. Additional temporal changes await the development of a more refined stratigraphy and a more thorough understanding of the meaning of our factors.

\section{CONCLUSIONS}

1. Comparison of spectral data measured from wet Amazon Fan sediments aboard the JOIDES Resolution using a handheld spectrophotometer (Minolta CM-2002) with spectral data derived from dry Amazon Fan sediment samples using a laboratory-grade spectrophotometer (Perkin-Elmer Lambda 6) produces surprisingly comparable results when the first-derivative curves derived from raw percent-reflectance curves are used for the comparison. If wavelengths $<430 \mathrm{~nm}$ are eliminated because of instrumental differences, and the bias from Saran Wrap used to cover the wet cores is taken into account, then the shapes of the wet and dry first-derivative curves show almost a 1:1 correlation. Absolute values of the first-derivatives derived from wet percent-reflectance curves are smaller and produce first-derivative curves in which variations are muted compared to curves from the dry measurements.

2. Factor analysis performed on a shore-based data set of dry, prepared core samples produced at least seven interpretable factors, whereas factor analysis of a shipboard data set derived from analysis of wet sediments yielded only four factors. However, the four factors identified in the shipboard data set are also present in the shore-based data set. Although the factors differ in their relative importance in the data sets (i.e., explain different amounts of variance), the overall shapes of the factor patterns are similar, which indicates that the same sediment components are being extracted from the wet and dry spectra. The shipboard results appear more muted, that is they contain less information, probably because wet samples were analyzed, although use of Saran Wrap and differences in instrumentation cannot be ruled out as causes.

3. The first four factors of the shipboard analyses and the comparable factors from the shore-based analyses may be interpreted in terms of sediment composition. These factors apparently represent hematite and goethite, clay minerals, organic matter, and carbonate.

4. Analysis of the entire wavelength range of the shore-based data set results in six factors each explaining more than $1 \%$ of the variance. These factors represent in order of decreasing variance explained organic matter, goethite, illite and montmorillonite, chlorite, hematite, and carbonate contents. When factor scores for each of these factors are plotted downhole, the resulting curves appear, in some intervals, to reflect temporal relationships related to fluctuations in fan sedimentation caused by glacio-eustatic sea-level fluctuations. In addition, various fan units and deposits (e.g., levees, HARP units, masstransport deposits, and hemipelagic sediments) appear to show somewhat characteristic factor scores for some factors.

5. The results of our comparisons of shipboard vs. shore-based data sets allow us to suggest a number of recommendations (listed below) that should be employed when collecting spectral data aboard the JOIDES Resolution.

\section{RECOMMENDATIONS FOR USING THE MINOLTA COLOR SCANNER}

\section{Use of Plastic Food Wrap to Cover Wet Cores During Scanning}

If plastic food wrap is used to cover cores during scanning, we strongly recommend that only the brand Glad Cling Wrap (crystal clear polyethylene) be used. Testing of several brands of food wrap revealed that Glad Cling Wrap is the only one tested that transmits light uniformly across the VIS and has minimal effect on spectra (see Fig. 2 and discussion above). Saran Wrap, which was used aboard the JOIDES Resolution prior to Leg 164, causes a decrease in reflectance at the violet end of the spectrum and transmits light less uniformly across the spectrum, and thus is less preferable than Glad Cling Wrap.

\section{Calibration of the Minolta CM-2002}

Do not use the Glad Cling Wrap, or any other plastic wrap, to cover the white calibration cap when calibrating the Minolta instrument. During calibration the instrument is expecting to receive a particular set of reflectance values from the white cap that are stored in the instrument's memory card. These values are not uniform throughout the VIS, but tend to decrease toward the violet end of the spectrum (see Fig. 1 and discussion in text).

\section{SCE vs. SCI Setting}

The Minolta CM-2002 has a switch that allows the specular component to be included (SCI) or excluded (SCE). Including the specular component (SCI) essentially includes glare and provides a better estimate of color as seen by the human eye. However, glare does not contribute to the spectrum reflected from the sediments. We recommend setting the switch to SCE. The SCE setting should provide better data for determining sediment mineralogy and composition, and should provide data that are more easily compared with data gathered by diffuse-reflectance (SCE setting only) laboratory spectrophotometers (see discussion in text and Table 1).

\section{Granular-Materials Cover Set (CM-A40)}

A glass lens with a vinyl cover can be attached to the Minolta CM2002 instrument to protect it when measuring wet materials, powders, etc. Please note, however, that the instructions for the GranularMaterials Cover say that "Data measured with the CM-2002 inside the Cover may be different than data measured with the CM-2002 alone." We therefore recommend that wet cores be covered with Glad Cling Wrap rather than using this cover. 


\section{Timing of Spectral Measurements Aboard Ship}

Because dewatering and oxidation change the characteristics of the sediment, it may be best to wait as long as possible during core description and processing before taking spectral readings. Changes related to dewatering take place rapidly at first and then become more slow. Oxidation is a slower process.

\section{REFERENCES}

Balsam, W.L., and Deaton, B.C., 1991. Sediment dispersal in the Atlantic Ocean: evaluation by visible light spectra. Rev. Aquat. Sci., 4:411-447.

, 1996. Determining the composition of late Quaternary marine sediments from NUV, VIS, and NIR diffuse reflectance spectra. Mar. Geol., 134:31-55.

Balsam, W.L., and Wolhart, R., 1993. Sediment dispersal in the Argentine Basin: evidence from visible light spectra. Deep-Sea Res. Part A, 40:1001-1031.

Barranco, F.T., Jr., Balsam, W.L., and Deaton, B.C., 1989. Quantitative reassessment of brick red lutites: evidence from reflectance spectrophotometry. Mar. Geol., 89:299-314.

Chester, R., and Elderfield, H., 1966. The infra-red determination of total carbonate in marine carbonate sediments. Chem. Geol., 1:277-290.

, 1968. The infra-red determination of opal in siliceous deep-sea sediments. Geochim. Cosmochim. Acta, 32:1128-1140.

Chester, R., and Green, R.N., 1968. The infra-red determination of quartz in sediments and sedimentary rocks. Chem. Geol., 3:199-212.

Damuth, J.E., 1977. Late Quaternary sedimentation in the western equatorial Atlantic. Geol. Soc. Am. Bull., 88:695-710.

Damuth, J.E., and Fairbridge, R.W., 1970. Equatorial Atlantic deep-sea arkosic sands and ice-age aridity in tropical South America. Geol. Soc. Am. Bull., 81:189-206.

Damuth, J.E., Flood, R.D., Kowsmann, R.O., Belderson, R.H., and Gorini, M.A., 1988. Anatomy and growth pattern of Amazon deep-sea fan as revealed by long-range side-scan sonar (GLORIA) and high-resolution seismic studies. AAPG Bull., 72:885-911.

Damuth, J.E., and Kumar, N., 1975. Amazon Cone: morphology, sediments, age, and growth pattern. Geol. Soc. Am. Bull., 86:863-878.

Deaton, B.C., 1987. Quantification of rock color from Munsell chips. J. Sediment. Petrol., 57:774-776.

Deaton, B.C., and Balsam, W.L., 1991. Visible spectroscopy: a rapid method for determining hematite and goethite concentrations in geological materials. J. Sediment. Petrol., 61:628-632.

, 1993. Identifying production zones with NUV/VIS/NIR spectra: examples from the Caddo Limestone and Strawn Sand. Geol. Soc. Am., Abstr. Programs, 25:8.
Flood, R.D., Piper, D.J.W., Klaus, A., et al., 1995. Proc. ODP, Init. Repts., 155: College Station, TX (Ocean Drilling Program).

Gaffey, S., 1985. Reflectance spectroscopy in the visible and near-infrared (0.35-2.55 micron): applications in carbonate petrology. Geology, 13:270-273.

Goddard, E.N., Trask, P.D., De Ford, R.K., Rove, O.N., Singewald, J.T., and Overbeck, R.M., 1948. Rock color chart. Geol. Soc. Am.

Herbert, T.D., Tom, B.A., and Burnett, C., 1992. Precise major component determinations in deep-sea sediments using Fourier Transform Infrared Spectroscopy. Geochim. Cosmochim. Acta, 56:1759-1763.

Jones, G.A., and Kaiteris, P., 1983. A vacuum-gasometric technique for rapid and precise analysis of calcium carbonate in sediments and soils. J. Sediment. Petrol., 53:655-660.

McGeary, D.F.R., and Damuth, J.E., 1973. Postglacial iron-rich crusts in hemipelagic deep-sea sediment. Geol. Soc. Am. Bull., 84:1201-1212.

Mix, A.C., Harris, S.E., and Janecek, T.R., 1995. Estimating lithology from nonintrusive reflectance spectra: Leg 138. In Pisias, N.G., Mayer, L.A., Janecek, T.R., Palmer-Julson, A., and van Andel, T.H. (Eds.), Proc. ODP, Sci. Results, 138: College Station, TX (Ocean Drilling Program), 413427.

Mix, A.C., Rugh, W., Pisias, N.G., Veirs, S., Leg 138 Shipboard Sedimentologists (Hagelberg, T., Hovan, S., Kemp, A., Leinen, M., Levitan, M., Ravelo, C.), and Leg 138 Scientific Party, 1992. Color reflectance spectroscopy: a tool for rapid characterization of deep-sea sediments. In Mayer, L., Pisias, N., Janecek, T., et al., Proc. ODP, Init. Repts., 138 (Pt. 1): College Station, TX (Ocean Drilling Program), 67-77.

Richardson, D.S., 1974. The origin of iron-rich layers in sediments of the western equatorial Atlantic Ocean (Ph.D. thesis). Columbia Univ., New York.

Schneider, R.R., Cramp, A., Damuth, J.E., Hiscott, R.N., Kowsmann, R.O., Lopez, M., Nanayama, F., Normark, W.R., and Shipboard Scientific Party, 1995. Color-reflectance measurements obtained from Leg 155 cores. In Flood, R.D., Piper, D.J.W., Klaus, A., et al., Proc. ODP, Init. Repts., 155: College Station, TX (Ocean Drilling Program), 697-700.

Shipboard Scientific Party, 1995. Explanatory notes. In Flood, R.D., Piper, D.J.W., Klaus, A., et al., Proc. ODP, Init. Repts., 155: College Station, TX (Ocean Drilling Program), 47-81.

Date of initial receipt: 4 December 1995

Date of acceptance: 31 May 1996

Ms 155SR-210 